Portland State University

PDXScholar

$1-1-2011$

\title{
Foreign Language Students' Beliefs about Homestays
}

Sara Racheal Juveland

Portland State University

Follow this and additional works at: https://pdxscholar.library.pdx.edu/open_access_etds Let us know how access to this document benefits you.

\section{Recommended Citation}

Juveland, Sara Racheal, "Foreign Language Students' Beliefs about Homestays" (2011). Dissertations and Theses. Paper 289.

https://doi.org/10.15760/etd.289

This Thesis is brought to you for free and open access. It has been accepted for inclusion in Dissertations and Theses by an authorized administrator of PDXScholar. Please contact us if we can make this document more accessible: pdxscholar@pdx.edu. 
Foreign Language Students' Beliefs about Homestays

by

Sara Racheal Juveland

A thesis submitted in partial fulfillment of the requirements for the degree of

Master of Arts

in

Teaching English to Speakers of Other Languages

Thesis Committee:

Nike Arnold, Chair

Kimberley Brown

Julie Haun

Portland State University

(C)2011 


\begin{abstract}
Language students who study abroad are often presented with multiple housing options. Living with a host family in a homestay is widely believed to be the most beneficial option for students with regards to language acquisition. However, little research has been done as to what students believe about homestays and how their beliefs may affect their choice of housing when studying abroad. In this study, 116 language students completed the Student Beliefs About Homestays Questionnaire. Both quantitative and qualitative data were gathered and analyzed to gain insight into what students believe about homestays. The results indicated that students in general value homestays not only for the opportunity for language acquisition, but also for the inside look at the family life and culture of the host country and for the support a family setting may provide to a student living abroad. Student beliefs about negative aspects of homestays (such as the possibility of being placed with a bad family) and the desired role of the homestay placement program were also investigated and several practical implications were drawn for staff both in homestay placement programs and language institutions that may serve to improve the homestay experience for all involved.
\end{abstract}




\section{Dedication}

This thesis is dedicated to the host family I stayed with the first time I studied abroad in Japan, as well as to everyone at Okazaki Megumi Kirisuto Kyokai (Okazaki Megumi Christ Church) who were my family and support network during my second trip abroad, when I stayed in a dormitory. It is also dedicated to all students thinking about studying abroad and considering taking the leap of trying to live with strangers for a week, 6 months, a year, or more. Finally, it is dedicated to my grandmother who, although she has never seriously studied a foreign language and has no interest travelling far from home, has always supported me in my travels and been excited to hear about my adventures abroad. 


\section{Acknowledgements}

I am thankful for everyone who has had a hand in this research. First, for Keith Walters and Lynn Santelmann, who were the first two professors I bounced the idea of doing research on student housing options off of during my first term in the MA TESOL program at PSU, before this study had any form or shape. Second, for Kim Brown, whose course Understanding the International Experience helped me to see the value of investigating phenomena from the perspective of those who have experienced them (and of looking to my own lived experiences for ideas and knowledge), and for serving as one of the members of my thesis committee. Next, for Susan Conrad, whose course Research Methods allowed me to begin structuring my study, and who allowed me to talk through statistics problems with her near the end of the writing of the thesis when I was stuck. I am very thankful for Nike Arnold for agreeing to be my advisor and working with me on this project, for helping improve and polish this thesis in innumerable ways, for helping me create the Student Beliefs About Homestays Questionnaire, and for always being available while I was working on the thesis. I am also thankful for Julie Haun, who allowed me to interview her early on in the process of creating the questionnaire and who also agreed to serve as one of the members of my thesis committee. I am thankful for HyunJin Park, for encouraging me throughout the whole process. And finally, I am thankful for all of the students who agreed to participate in this study and add their voices to the research on homestays. 


\section{Table of Contents}

i. Abstract

ii. Dedication

iii. Acknowledgements

iv. List of Tables

1. Introduction

2. Literature Review

14. Purpose and Research Questions

15. Methodology

34. Results and Discussion: Research Question 1

77. Results and Discussion: Research Question 2

93. Conclusions

100. Practical Implications

106. Limitations of the Study

108. Suggestions for Further Research

111. References

116. Appendix: Student Beliefs About Homestays Questionnaire 


\section{List of Tables}

15-16. Table 1: Participants' Native Languages and Languages Being Studied 18-20. Table 2: Categories Investigated and Their Corresponding Items

24-26. Table 3: Sources From Which Items Were Created

28. Table 4: Examples of Reverse-Coded Items

34-35. Table 5: Results of Likert-scale Items

35. Table 6: Results of the Likert-scale Items Presented by Category

45-46. Table 7: Item \#1 Results

52-53. Table 8: Item \#2 Results

58. Table 9: Item \#3 Results

67. Table 10: Item \#4 Results

73. Table 11: Item \#5 Results

75. Table 12: Item \#6 Results

77-79. Table 13: Results of Likert-scale items for each group of students

79-80. Table 14: Results for categories split by student group 


\section{Introduction}

Students who choose to study abroad usually have various housing options available to them, and homestays are often one of the options that study abroad programs attempt to provide for their incoming students. When students are filling out study abroad housing applications and have to choose between several different options, what beliefs motivate them to choose or decline a homestay? Although the environment in which students reside can shape their perceptions of the entire study abroad experience, Schmidt-Rinehart and Knight (2004) have reported that "[s]urprisingly, [...] the homestay component is one of the least studied parts of the study abroad experience" (p. 254). The purpose of this study is to add to the literature regarding the homestay component of study abroad from the perspective of the students by investigating their beliefs about homestays using a questionnaire. 


\section{Literature Review}

I begin with a review of the literature regarding homestays in general. Research on the effectiveness of homestays with regard to language gain is surveyed in order to highlight the general assumptions that surround homestays in the field of language education. I then review literature having to do with students' expectations of their homestays, highlighting research that shows the results from the students' perspective of both positive and negative homestay experiences. I move on to literature about homestay placement programs and suggestions that have been made in order to better facilitate the homestay experience for the student. Following this, I present research on student beliefs to illustrate how the beliefs that students hold about various aspects of their language learning experiences influence choices they make while learning; for example, students' beliefs about languages and language learning may influence which learning and testtaking strategies they choose to use. Since beliefs influence choices students make in some areas of their study, it is plausible that they also influence choices made about housing options while abroad. It is the investigation of those beliefs that is the chief aim of this study.

\section{Effect of the Homestay With Regard to Language Gain}

Placement in a homestay, while often more expensive than other options, is a popular choice for students studying abroad. Students generally believe that living with a host family will positively influence their language gain. A major motivation for studying abroad is the high potential for exposure to the target language outside of the 
classroom (Freed, 1998; Ife, 2000); staying with a host family is believed to be a surefire way of gaining chances for interaction with native speakers (Fryer \& Lukasevich, 1998; Gutel, 2007; Kaplan, 1989; Vande Berg, 2007; Yager, 1998). Knight and SchmidtRinehart (2010) reported "that the majority of students state that their number one goal in studying abroad is to increase their language skills. We also know that the best way to do this is to interact with native speakers" (p. 76). Wilkinson (2002) likewise reported that American undergraduate students view homestays as "offering the greatest potential for conversational contact with native speakers" (p. 157). From these statements, we can see the widely held belief that simply being around native speakers serves to promote language acquisition.

One of the reasons students consider this belief to be common sense may be the proliferation of statements in study abroad program brochures such as one quoted in Wilkinson (1998b): "the fastest way to become fluent in a language is to live in the host country with a family that has limited English skills" (p. 23). A book for American high school students preparing to study abroad, The Exchange Student Survival Kit, paints this rosy picture of the homestay:

Living with a host family is an exciting and challenging way to discover a new country and culture. As an exchange student, you have the chance to join in the daily life of a family and a community of friends. [...] In living with a family you will be able to learn the language and come to understand the culture and way of life of your host country in much the same way that you learned your own 
language and absorbed and came to understand your own culture. (Hansel, 2007, p. 15)

Literature such as these two examples may help students and many educators form the general belief that homestays are unquestionably beneficial for students studying a language abroad.

Some researchers, however, have raised concerns about the generalization that the best way to interact with native speakers is to live with a host family, claiming that a homestay, simply by virtue of being a homestay, will not always benefit language gain (Magnan \& Back, 2007; Wilkinson, 2002). Freed, So, and Lazar (2003) went so far as to question the unqualified belief that study abroad is usually, if not always, beneficial to language acquisition, stating that although "immersion in the native speech community $[\ldots]$ has often been described as one of the surest ways to acquire fluency in a second language $[\ldots]$ there is little empirical evidence to support [this belief]" (p. 34).

In a study comparing data from students studying Russian while living in dormitories with data from students living with host families, Rivers (1998) found that the homestay was "a negative predictor for Speaking gain, [had] no apparent effect on Listening, and [was] a positive predictor for Reading gain" (p. 496). These findings are counterintuitive to the expectations of the virtues of a homestay; it would be expected that students staying with a family of native Russian speakers would improve their speaking and listening skills more than students staying in dormitories with other students who are studying abroad. Rivers did mention two important caveats to keep in mind 
concerning his study: first, the data collected were for students studying at two different periods in time, since for many years foreign students could only live in dormitories, and second, that the homestay sample $(n=126)$ was barely large enough to run a logistic regression analysis, while the dorm-stay sample $(n=2,224)$ was quite large.

In another study comparing students living in a homestay with those living in dormitories, Magnan and Back (2007) compared the Oral Proficiency Interview scores of American students studying in France; no significant difference was found for oral improvement between students living with native French speakers $(n=11)$ and those living alone or with non-native speakers of French $(n=9)$. Studies such as these indicate that the homestay may not always have a positive influence on language acquisition.

\section{Students' Expectations of Their Host Family}

Other studies have pointed out that the factors influencing the outcome of homestays are more numerous than simply the opportunity for exposure to the language being studied (Churchill, 2003; Gutel, 2007; Iino, 2006; Kendall-Smith \& Rich, 2003; Tanaka, 2007; Wilkinson, 1998a; Wilkinson, 2000; Woodall \& Takeuchi, 1999). Wilkinson (1998a) conducted a qualitative study of students participating in a summer program in France. While one of the students became like a member of the host family, spent time doing activities with the family, made plans to visit the family the following year, and even changed her major from biology to French after the summer program, another student reported that her host family ignored her and that she spoke roughly three sentences a day to her family. She ended her course of study 4 weeks early and 
considered dropping her French minor. Both students began their homestay with expectations that their host family would welcome them as a member of the family, would help them practice their French, and would teach them about French culture. The first student's expectations were met, and she ended her study abroad experience with a positive outlook on France, French culture, and French people, largely due to her homestay experience. The second student's experiences, however, did not match her expectations, and she ended the program with a negative view not only of her particular host family, but of France, French culture, and French people in general. Clearly, these students entered a homestay with pre-formed beliefs about what they could gain by living with a French family rather than in a dormitory, and the degree to which their expectations were met influenced not only their perception of homestays but also their perceptions of the country, culture, and language they were immersed in.

In another study, Wilkinson (2002) noted that many students expect their host families to play the role of language teacher and that the degree to which the host family members fulfill this role can also impact how students view their experiences abroad and the value of the homestay. The theme of met or unmet expectations during a homestay is found in other research as well. Tanaka (2007), who studied 29 Japanese students studying in New Zealand, stated that

[w]hile some host families provide an excellent living and L2 learning environment for their students [...] others pay little attention to their homestay students and do not fit in with students' expectations. Accordingly, students' 
opinions about their homestay experience were divided. (Tanaka, 2007, p. 39)

In the same way that the beliefs of the American students in Wilkinson's study led them to form many expectations for their French hosts, the Japanese students in Tanaka's study held beliefs about homestays that led them to expect hosts to provide them with many opportunities to use English, to welcome them into their families, and to help them learn about the culture of New Zealand. Some students whose expectations were met reported that "their desire to communicate with their hosts and learn English increased" (p. 44). Many of the students, however, did not receive the experience they had expected. In interviews, students mentioned that their low proficiency in English prevented them from spending much time communicating with their hosts. Many students were shy and reported feeling that they would bother or disturb their hosts by speaking too much. Other students simply preferred to spend their free time with Japanese peers, speaking Japanese.

Again, the motivation for choosing a host family while studying abroad can differ among students depending on what they believe about host families and expect to gain from their trip. When a host family does not meet their expectations, students may respond in various ways. Woodall and Takeuchi (1999) reported findings similar to Tanaka's in their qualitative study of 4 Japanese students studying in the state of Washington. In interviews, the students reported feeling that they were not able to use English as much as they had hoped and complained that when their host families did speak with them, it was often in a modified foreigner talk that did not challenge the 
students, so that they felt that they were not able to achieve the language gains that they had expected from interacting with native speakers.

\section{The Role of the Homestay Placement Program}

It appears that, in order for students to be able to form the most realistic expectations about their homestay experiences before studying abroad, programs should strive to provide students and host families with more accurate pre-departure information. In a study of Japanese high school students studying in Canada, Crealock, Derwing, and Gibson (1999) reported that the students' expectations of the homestay were not met because they were not able to make realistic predictions in the first place due to the lack of information given to them before leaving Japan and the lack of program support for their emotional well-being and adjustment to a new culture. These factors "had negative effects on what should have been a rewarding experience" (Crealock et al., 1999, p. 59).

Researchers have asserted that programs should inform students of the conditions of their homestay, the make-up of their host family, and reasonable expectations about the amount of language gain they can expect, as well as provide stable support for the duration of the homestay experience; in addition, host families should also be given some sort of training or information regarding their incoming students (Campbell, 2004;

Crealock et al., 1999; Fryer \& Lukasevich, 1998; Kendall-Smith \& Rich, 2003; Rivers, 1998; Schmidt-Rinehart \& Knight, 2004). However, in order to provide information to students about how to form reasonable expectations, providers must first have a grasp of the beliefs that students have about homestays. Furthermore, since some students choose 
homestays and some do not, it is in the interest of homestay placement programs to discover whether there are underlying beliefs about homestays influencing these decisions and, if so, what they are. The purpose of this thesis is to investigate those beliefs.

\section{The Importance of Students' Beliefs}

Beliefs have been shown to influence students' actions and evaluations of experiences. In the field of language acquisition in particular, several researchers have found that students' beliefs influence the choices that they make with regard to language learning strategy (Liao, 2006; Mori, 1999; Peacock, 1999; Victori, 1999; Yang, 1999), with regard to changes in their choices of strategies as new beliefs emerge (Hosenfeld, 2003), and with regard to the decision of whether or not to continue their foreign language study (Fernandez, 2008). Although no studies were found with regard to student beliefs about homestays in particular, it can be assumed that if student beliefs influence choices made in other areas of their language education they will also influence choices made in the area of housing while studying abroad. The following review of studies on various aspects of student beliefs serves to show that beliefs have been found to influence or be otherwise related to the choices students make while learning a second language.

Peacock (1999) administered a proficiency test and a slightly modified version of the Beliefs About Language Learning Inventory to 155 students of English at a college in Hong Kong. He found that there were several correlations between beliefs and 
proficiency; for example, students who believed "that being allowed to make mistakes in the beginning meant they would find it hard to get rid of them later on were significantly less proficient than learners who thought otherwise" (p. 258). Furthermore, students "who believed that they should not say anything in the foreign language until they could say it correctly were significantly less proficient than [those] who did not" (p. 258). The beliefs held by these students could correlate with low proficiency because students are likely to choose learning strategies that match their beliefs; not speaking while trying to learn a language for fear of making mistakes is one way to hamper acquisition and could have led to these students' low proficiency.

In a study investigating students' learning strategy beliefs and their actual use of various translation strategies while learning, Liao (2006) found evidence that suggests that students' beliefs about translation influenced the types of translation strategies they chose to use while studying English. In particular, out of the 351 Taiwanese students who participated in the study, those who were majoring in a foreign language tended to believe that translation activities would negatively affect their English acquisition and avoided them, whereas students with non-foreign language majors believed that translation activities would assist them in their language acquisition and used them more often.

Mori (1999) also found correlations between learner beliefs and strategy choice. Mori examined the beliefs and strategy use of 47 students of Japanese regarding the study of kanji compounds. Kanji are Chinese characters used in Japanese; each character has at 
least one meaning and unique pronunciation, although they may have more. Although some kanji stand for words on their own, many thousands of words are constructed by combining two or more kanji together to form a compound. The meaning of the compound is not always apparent simply from the original meaning of the two separate kanji used to create the compound. Various interpretation strategies are used by students when they come across an unknown kanji compound; it is these strategies that Mori investigated in her study. Mori administered a questionnaire and a kanji compound test to students and found correlations between students' stated beliefs on the questionnaire and the strategies they used on the test suggesting that "the use of word inference strategies can be at least partially accounted for by the learners' beliefs about learning in general and language learning in particular" (p. 542).

The effect of learners' beliefs, not on language strategy choice, but on broader decisions which impact their language study career as a whole, was investigated by Fernandez (2008) in a study focused on discerning if there was a difference in the beliefs of students who chose to continue language study or abandon it upon completing the graduation requirement. Fernandez broke the 324 participants in her study into three groups: those who intended to continue their language study in the following quarter, those who intended to eventually continue their language study but not in the following quarter, and those who did not intend to continue their language study. She administered a questionnaire to students and found differences among the groups with regard to beliefs about such topics as language aptitude, ease of learning a foreign language, confidence in 
their ability to learn a language well, translation, culture, and job expectations.

Thus, in addition to the choice of learning strategies and other actions taken by students while studying in or outside of the classroom, beliefs can influence the choices students make with regards to studying a language in general, including choices pertaining to study abroad. Laubscher (1994) conducted a qualitative study of 30 students studying abroad, and stated that "[s]tudents' preconceptions will necessarily influence the way they approach their programs abroad" (p. 18). Not only can the beliefs that students hold influence their actions, but by simply being aware of students' beliefs, others involved in the students' education can modify their actions to better facilitate students' learning. As Horwitz (1988) states,

Foreign language teachers can ill afford to ignore these beliefs [...]. Knowledge of learner beliefs about language learning should also increase teachers' understanding of how students approach the tasks required in language class and, ultimately, help teachers foster more effective learning strategies in their students. (p. 293)

In the same way, simply being aware of the beliefs that students hold regarding homestays can increase the program administrators' ability to assist students in forming realistic expectations about homestays and to match students with host families so that these expectations have the highest potential of being met. Sakui and Gaies (1999) also suggest that research on language students' beliefs be used "as a component of policy and program evaluation" (p. 487). The beliefs that this study seeks to investigate are 
pertinent to the staff of study abroad programs who counsel students that are interested in study abroad and wish to learn about the homestay as a housing option. 


\section{Purpose and Research Questions}

The purpose of this study is to investigate the beliefs that students studying a foreign language have about homestays. Identifying commonly held beliefs can assist faculty and staff involved in language teaching, study abroad, and homestay administration programs to better understand their students, to develop training and orientations for their students, and to maximize the potential benefits of the homestay experience. This study investigates the following two questions:

\section{Research Questions:}

1. What are the beliefs that students studying a foreign language have about homestays?

2. Do the beliefs of the following three groups of students differ from each other? If so, how?

a. Homestay Group: Students who have completed or are currently in a homestay.

b. Future Homestay Group: Students who have not completed a homestay and are not currently in a homestay but plan to complete one.

c. No Homestay Group: Students who have not completed a homestay and do not intend to do so. 


\section{Methodology}

\section{Context of the Study}

This study took place at Portland State University (PSU), a large, public university in Oregon. The university includes an Intensive English Language Program (IELP) for students from abroad studying English. The university also offers classes in 24 foreign languages for regularly admitted students.

\section{Participants}

The participants in this study were students studying a foreign language at PSU. Data was collected from a total of 116 students. To qualify to participate in this study, students had to be in the upper three levels of the IELP or currently enrolled in a foreign language course at PSU. The level requirement for the IELP students was necessary to ensure that the students could understand and respond to the survey, which was in English. There were a total of 74 male respondents and 42 female respondents. The average age of the respondents was 24 (ages ranged from 18 to 64). Table 1 shows the native languages of the speakers and the languages currently being studied (the total for the languages currently being studied is over 116 because some students listed 2 languages that they are concurrently studying).

Table 1

Participants' Native Languages and Languages Being Studied

\begin{tabular}{|l|c|c|c|c|c|c|}
\hline \multirow{3}{*}{$\begin{array}{l}\text { Native } \\
\text { Language }\end{array}$} & Arabic & Chinese & English & Indonesian & Japanese & \multirow{2}{*}{ Total } \\
\cline { 2 - 6 } & 38 & 13 & 45 & 1 & 6 & \multirow{2}{*}{116} \\
\cline { 2 - 7 } & Korean & Norwegian & Russian & Spanish & Vietnamese & 1 \\
\cline { 2 - 6 }
\end{tabular}




\begin{tabular}{|l|c|c|c|c|c|c|}
\hline $\begin{array}{l}\text { Language } \\
\text { Being } \\
\text { Studied }\end{array}$ & English & French & German & Japanese & Russian & Total \\
\cline { 2 - 7 } & 67 & 33 & 4 & 1 & 16 & 121 \\
\hline
\end{tabular}

\section{The Questionnaire}

To compare the beliefs of three different groups of students on various aspects of homestays, it is preferable to collect data from as large a sample of students as possible so that each group can be sufficiently represented and so that statistical analyses can be run on the data collected. After reviewing student belief literature, I decided to compose a questionnaire for this study in order to meet those needs. Although structured, semistructured, and open interviews can be used to collect data on student beliefs, the amount of time required to conduct, transcribe, and analyze the data from interviews prohibits the size of feasible samples. Students may also be less likely to volunteer for a timeconsuming interview, which would further limit the sample size. Observation of students can also be used to record and analyze the effects of student beliefs in action (Cowie, 2009), but in the case of this study the observation of the results of the beliefs (did a student, in the end, choose a homestay or not; how did students in a homestay perceive their experiences) would not only be unfeasible but also would not allow the researcher access to the underlying beliefs themselves. A questionnaire, however, can be administered in a relatively short period of time to a large number of students, and the results can easily be organized and analyzed for differences between groups.

Questionnaires have been widely used in second language acquisition research to discover the beliefs that students hold about various aspects of language learning 
(Cotterall, 1999; Fernandez, 2008; Horwitz, 1988; Liao, 2006; Mori, 1999; Peacock, 1999; Rifkin, 2000; Sakui \& Gaies, 1999; Yang, 1999). It is possible to use these questionnaires to compare the beliefs held by different groups of students to ascertain whether their beliefs are related to or influence actions such as choice of language learning strategy or approach to language learning in general (Fernandez, 2008; Peacock, 1999; Rifkin, 2000). In the same way, a questionnaire regarding beliefs about homestays can be used to investigate differences between groups of students and whether differences in beliefs are related to the choices students make regarding housing options while studying abroad.

Drawbacks to questionnaires include the issues of validity and reliability with regard to how the questionnaire items were constructed. It is possible to create questionnaires quickly that may appear to target the phenomenon under study but do not in fact elicit responses related to that phenomenon, making them invalid. Furthermore, care must be taken to word items neither too ambiguously (to avoid confusion) nor too simply (to avoid making only a shallow, superficial investigation into the phenomenon in question). Steps such as reverse-coding items and using multi-item scales also need to be taken to increase reliability. The researcher should address these issues while constructing the questionnaire (D $\square$ rnyei, 2003; D $\square$ rnyei, 2007).

For this study, I constructed a 5-point Likert-scale questionnaire with items pertaining to beliefs about homestays (Student Beliefs About Homestays Questionnaire). In accord with Cotterall's (1999) assertion that "there is value in investigating learner 
beliefs using both qualitative and quantitative approaches" (p. 497) and to collect data from a second perspective that can be used to further our understanding of the quantitative data (Brown, 2009), the questionnaire includes some open ended questions to collect qualitative data in addition to Likert-scale items. The questionnaire also collects demographic information about the students so that they can be grouped and compared in a later analysis. The participants' names were not recorded.

\section{Questionnaire: Construction and Content}

The questionnaire items were developed based on the following four areas: 1) my experience with study abroad, 2) my review of the literature pertaining to study abroad, homestays, and student beliefs, 3) a pool of possible items gathered from discussions I have had with my advisor and other faculty and staff in the Applied Linguistics Department and the IELP at PSU, and 4) casual conversations with students studying foreign languages. Based on these factors, I developed seven categories to investigate. Each category is represented by four items in the questionnaire, for a total of 28 Likertscale items. The categories are Homestays and Language Acquisition, Homestay Program, Culture, Interaction with Native Speakers, Multiple Boarders, Dependence on Host Family, and Open Communication. In Table 2 I list the major categories the questionnaire targets and the items associated with each category (with their number in the questionnaire, assigned by a random number generator).

Table 2

Categories Investigated and Their Corresponding Items 


\begin{tabular}{|c|c|}
\hline Category & Items \\
\hline $\begin{array}{l}\text { A. Homestays and Language } \\
\text { Acquisition }\end{array}$ & $\begin{array}{l}\text { 14. Living with a host family will improve my grammar. } \\
\text { 17. Every student studying a foreign language abroad should live } \\
\text { with a host family. } \\
\text { 22. I will practice the language more living with a host family } \\
\text { than in a dormitory. } \\
\text { 23. Living with a host family will improve my pronunciation. }\end{array}$ \\
\hline B. Homestay Program & $\begin{array}{l}\text { 6. If I have any problems, the homestay program will help me. } \\
\text { 9. The homestay program should let me communicate with my } \\
\text { host family before I leave my country. } \\
\text { 12. I can trust a homestay program to find a good host family for } \\
\text { me. } \\
\text { 20. The best homestay program will give me a thorough } \\
\text { orientation about living with a host family. }\end{array}$ \\
\hline C. Culture & $\begin{array}{l}\text { 2. Living with a host family is the best way to experience a new } \\
\text { culture. } \\
\text { 18. I will not learn about the host country's culture if I live in a } \\
\text { dormitory. } \\
\text { 19. A host family will teach me about their country's culture. } \\
\text { 21. I will learn more about the country's culture if I live with a } \\
\text { host family. }\end{array}$ \\
\hline $\begin{array}{l}\text { D. Interaction with Native } \\
\text { Speakers }\end{array}$ & $\begin{array}{l}\text { 1. A host family will help me make friends with native speakers } \\
\text { of the language I am studying. } \\
\text { 3. I will meet more native speakers of the language I am } \\
\text { studying if I live with a host family than if I live in a dormitory. } \\
\text { 10. I will spend more time with people from my own country if I } \\
\text { live in a dormitory. } \\
\text { 11. A host family will introduce me to their friends and family. }\end{array}$ \\
\hline E. Multiple Boarders & 5. If more than one student lives with my host family, we will \\
\hline
\end{tabular}




\begin{tabular}{|c|c|}
\hline & $\begin{array}{l}\text { not be able to learn the language we are studying well. } \\
\text { 7. If there is more than one student living with my host family } \\
\text { we can spend time together. } \\
\text { 16. It is best if I am the only student living with my host family. } \\
\text { 28. It is okay if there is more than one student living with my } \\
\text { host family as long as we do not speak the same native language. }\end{array}$ \\
\hline $\begin{array}{l}\text { F. Dependence on Host } \\
\text { Family }\end{array}$ & $\begin{array}{l}\text { 4. My host family should not expect me to do chores (for } \\
\text { example: wash dishes, do laundry, watch children, clean the } \\
\text { house). } \\
\text { 24. My host family should treat me like one of their own } \\
\text { children. } \\
\text { 26. My host family should give me a key to their house. } \\
\text { 27. My host family should not tell me what time to come home } \\
\text { each night. }\end{array}$ \\
\hline G. Open Communication & $\begin{array}{l}\text { 8. It is rude to ask my host family to change something for me. } \\
\text { 13. If I disagree with my host family, I can tell them. } \\
\text { 15. Even if I don't like my host family's food, I cannot tell them. } \\
\text { 25. I cannot tell my host family if I am unhappy. }\end{array}$ \\
\hline
\end{tabular}

Each category has a polarization as follows: higher scores in Category A indicate that a homestay is believed to be helpful for language acquisition; in Category B, higher scores indicate that the homestay program should be helpful and involved in the process; in Category $\mathrm{C}$, higher scores indicate that a homestay is believed to be helpful for learning about the culture of the host country; higher scores in Category D indicate that a homestay is believed to provide more interaction with native speakers than a dormitory; 
in Category E, higher scores indicate that multiple boarders in a homestay are seen as beneficial; in Category F, higher scores indicate that students believe they should be less dependent on their host family; and finally, higher scores in Category $\mathrm{G}$ indicate that students believe they should be able to talk openly with their host family. The reverse coded items are Items 4, 5, 8, 15, 16, 24, and 25. In these instances, a lower score would indicate what a higher score usually would in that category.

In addition to the Likert-scale items, there are nine demographic items at the beginning of the questionnaire. Five of the demographic items are closed yes/no items, and four of the items are specific open items (items that ask for one specific piece of factual information, see $\mathrm{D} \square$ rnyei 2007, p. 107). These items will allow the comparison of the beliefs of different groups of students for this study and possible future analysis. The first three items ask about the respondent's previous and current experience with study abroad and homestays, and desire (or not) to stay with a host family in the future. This information will allow the students to be broken into the three groups to be investigated for Research Question 2. The other six items identify the respondent's native language, the language they are currently studying and length of time they have been studying it, languages they have studied in the past, gender, age, and if they have hosted an exchange student before. This information, while not specifically relevant to the two research questions in this study, will be used in a future study to further analyze the data by forming students into different groups.

Following the Likert-scale items are 6 open-ended items designed to allow the 
students to express their beliefs about homestays in their own words. The first two items investigate student beliefs about homestays by asking whether students see homestays as helpful for students studying a language in a foreign country (Item 1) or not and whether a homestay is necessary to learn a foreign language (Item 2) or not. The second two items investigate what students think is the best thing about homestays (Item 3) and the worst thing about homestays (Item 4). Item 5 asks students what advice they would give another student who is considering a homestay. Item 6 specifically targets students who have participated in a homestay before or are currently in a homestay to investigate whether they perceive their experience to have changed or be changing their beliefs about homestays. See Appendix A for a complete copy of the questionnaire.

\section{Validity}

Since no previous questionnaire on student beliefs about homestays was found, I personally developed the questionnaire for this study. The following actions were taken to ensure the validity of the questionnaire.

The items were constructed drawing from a wide range of sources pertaining to homestays including my own experiences studying abroad (which include a semester living with a host family and a 6-week term living in a student dormitory), informal conversations with IELP students studying here and American students who have studied or were studying other languages, a review of the study abroad literature (focusing on issues raised that relate in some way to living conditions), and interviews with faculty in the Applied Linguistics department at PSU and faculty and staff in the IELP at PSU. 
These sources produced a rich body of issues pertaining to homestays that I then grouped according to what specific aspect of the homestay experience they addressed. Although many aspects of the homestay experience occurred in these sources, in the interest of creating a questionnaire that was not prohibitively long, I choose seven categories pertaining to homestays to investigate with this questionnaire. The seven categories that I choose to investigate in the Likert-scale section of this questionnaire were those that came up most frequently and seemed to be given the most weight in the sources I consulted. As shown in Table 3, each item in the Likert-scale section of the questionnaire was mentioned in at least one publication and in conversations with language students, lending authority and face validity to the weight of these items when considering beliefs about homestays. In addition, many of the items were mentioned in interviews with faculty in the Department of Applied Linguistics at PSU or staff in the IELP and/or pertained in some way to my own personal experience of studying a language abroad.

Table 3 lists the sources for each item in the Likert-scale section of the questionnaire. Note that when an article is cited as a source, it is not necessarily the case that the view of the author of the article matches the wording of the item; rather it indicates that the topic that the item investigates was mentioned or investigated in some way in the source article(s). Likewise, when personal experience, informal conversations with students, or interviews with faculty or staff are cited, it is simply that the topic was mentioned, not necessarily that the source agrees with the orientation of the item itself. 
Table 3

Sources From Which Items Were Created

\begin{tabular}{|c|c|}
\hline Item & Source(s) \\
\hline $\begin{array}{l}\text { 1. A host family will help me make friends } \\
\text { with native speakers of the language I am } \\
\text { studying. }\end{array}$ & $\begin{array}{l}\text { - } \quad \text { PE, IC } \\
\text { Crealock (1999), Fryer and Lukasevich (1998), } \\
\text { Gutel (2007), Hansel (2007), Kaplan (1989), } \\
\text { Schmidt-Rinehart and Knight (2004), Tanaka } \\
\text { (2007), Wilkinson (1998a), Wilkinson (2002), } \\
\text { Woodall (1999), Yager (1998) }\end{array}$ \\
\hline $\begin{array}{l}\text { 2. Living with a host family is the best way } \\
\text { to experience a new culture. }\end{array}$ & $\begin{array}{ll}- & \text { PE, IC, FS } \\
\text { - } & \text { Campbell (2004), Crealock (1999), Gutel } \\
& \text { (2007), Hansel (2007), Kaplan (1989), } \\
& \text { Wilkinson (1998a), Yager (1998) }\end{array}$ \\
\hline $\begin{array}{l}\text { 3. I will meet more native speakers of the } \\
\text { language I am studying if I live with a host } \\
\text { family than if I live in a dormitory. }\end{array}$ & $\begin{array}{ll}\text { - } & \text { PE, IC } \\
\text { - } & \text { Crealock (1999), Fryer and Lukasevich (1998), } \\
\text { Gutel (2007), Hansel (2007), Iino (2006), } \\
\text { Kaplan (1989), Tanaka (2007), Wilkinson } \\
\text { (1998a), Woodall (1999), Yager (1998) }\end{array}$ \\
\hline $\begin{array}{l}\text { 4. My host family should not expect me to } \\
\text { do chores (for example: wash dishes, do } \\
\text { laundry, watch children, clean the house). }\end{array}$ & $\begin{array}{ll}- & \text { PE, IC, FS } \\
\text { - } & \text { Gutel (2007), Hansel (2007), Schmidt-Rinehart } \\
& \text { and Knight (2004) }\end{array}$ \\
\hline $\begin{array}{l}\text { 5. If more than one student lives with my } \\
\text { host family, we will not be able to learn the } \\
\text { language we are studying well. }\end{array}$ & $\begin{array}{l}\text { - IC, FS } \\
\text { - Churchill (2003), Fryer and Lukasevich (1998), } \\
\text { Gutel (2007), Schmidt-Rinehart and Knight } \\
\text { (2004) }\end{array}$ \\
\hline $\begin{array}{l}\text { 6. If I have any problems, the homestay } \\
\text { program will help me. }\end{array}$ & $\begin{array}{ll}\text { - } & \text { IC, FS } \\
\text { - } & \text { Campbell (2004), Crealock (1999) } \\
\end{array}$ \\
\hline $\begin{array}{l}\text { 7. If there is more than one student living } \\
\text { with my host family we can spend time } \\
\text { together. }\end{array}$ & $\begin{array}{ll}- & \text { IC, FS } \\
\text { - } & \text { Churchill (2003), Fryer and Lukasevich (1998), } \\
\text { Gutel (2007), Schmidt-Rinehart and Knight } \\
\text { (2004) }\end{array}$ \\
\hline $\begin{array}{l}\text { 8. It is rude to ask my host family to } \\
\text { change something for me. }\end{array}$ & $\begin{array}{ll}- & \text { PE, IC, FS } \\
\text { - } & \text { Campbell (2004), Iino (2006), Schmidt-Rinehart } \\
& \text { and Knight (2004) }\end{array}$ \\
\hline $\begin{array}{l}\text { 9. The homestay program should let me } \\
\text { communicate with my host family before I } \\
\text { leave my country. }\end{array}$ & $\begin{array}{ll}\text { - } & \text { PE, IC } \\
\text { - } & \text { Campbell (2004), Crealock (1999), Fryer and } \\
\text { Lukasevich (1998), Rivers (1998), Schmidt- } \\
\text { Rinehart and Knight (2004) }\end{array}$ \\
\hline $\begin{array}{l}\text { 10. I will spend more time with people } \\
\text { from my own country if I live in a } \\
\text { dormitory. }\end{array}$ & $\begin{array}{ll}- & \text { PE } \\
- & \text { IC } \\
\text { - } & \text { Gutel (2007), Iino (2006), Tanaka (2007), } \\
& \text { Wilkinson (1998a), Woodall (1999), Yager } \\
& (1998)\end{array}$ \\
\hline $\begin{array}{l}\text { 11. A host family will introduce me to their } \\
\text { friends and family. }\end{array}$ & $\begin{array}{ll}\text { - } & \text { PE, IC } \\
\text { - } & \text { Crealock (1999), Fryer and Lukasevich (1998), }\end{array}$ \\
\hline
\end{tabular}




\begin{tabular}{|c|c|}
\hline & $\begin{array}{l}\text { Gutel (2007), Hansel (2007), Kaplan (1989), } \\
\text { Schmidt-Rinehart and Knight (2004), Tanaka } \\
\text { (2007), Wilkinson (1998a), Wilkinson (2002), } \\
\text { Woodall (1999), Yager (1998) }\end{array}$ \\
\hline $\begin{array}{l}\text { 12. I can trust a homestay program to find a } \\
\text { good host family for me. }\end{array}$ & $\begin{array}{ll}- & \text { PE, IC, FS } \\
\text { - } & \text { Campbell (2004), Crealock (1999), Fryer and } \\
& \text { Lukasevich (1998), Rivers (1998), Schmidt- } \\
& \text { Rinehart and Knight (2004) } \\
\end{array}$ \\
\hline $\begin{array}{l}\text { 13. If I disagree with my host family, I can } \\
\text { tell them. }\end{array}$ & $\begin{array}{l}\text { - IC, FS } \\
\text { Campbell (2004), Fryer and Lukasevich (1998), } \\
\text { Gutel (2007), Schmidt-Rinehart and Knight } \\
\text { (2004) }\end{array}$ \\
\hline $\begin{array}{l}\text { 14. Living with a host family will improve } \\
\text { my grammar. }\end{array}$ & $\begin{array}{ll}- & \text { PE, IC } \\
\text { Campbell (2004), Freed (1998), Hansel (2007), } \\
\text { Ife (2000), Iino (2006), Tanaka (2007), } \\
\text { Wilkinson (1998a), Woodall (2002), Yager } \\
\text { (1998) }\end{array}$ \\
\hline $\begin{array}{l}\text { 15. Even if I don't like my host family's } \\
\text { food, I can't tell them. }\end{array}$ & $\begin{array}{ll}-\quad \text { PE, IC, FS } \\
\text { Campbell (2004), Fryer and Lukasevich (1998), } \\
\text { Gutel (2007), Hansel (2007), Kendall-Smith and } \\
\text { Rich (2003), Schmidt-Rinehart and Knight } \\
\text { (2004), Woodall (1999) }\end{array}$ \\
\hline $\begin{array}{l}\text { 16. It is best if I am the only student living } \\
\text { with my host family. }\end{array}$ & $\begin{array}{ll}\text { - } & \text { IC, FS } \\
\text { Churchill (2003), Fryer and Lukasevich (1998), } \\
\text { Gutel (2007), Schmidt-Rinehart and Knight } \\
\text { (2004) }\end{array}$ \\
\hline $\begin{array}{l}\text { 17. Every student studying a foreign } \\
\text { language abroad should live with a host } \\
\text { family. }\end{array}$ & $\begin{array}{ll}- & \text { IC } \\
- & \text { Iino (2006), Schmidt-Rinehart and Knight } \\
& \text { (2004), Wilkinson (1998b), Yager (1998) } \\
\end{array}$ \\
\hline $\begin{array}{l}\text { 18. I will not learn about the host country's } \\
\text { culture if I live in a dormitory. }\end{array}$ & $\begin{array}{ll}- & \text { PE, IC } \\
\text { - } & \text { Fryer and Lukasevich (1998), Gutel (2007), } \\
\text { Kaplan (1989), Schmidt-Rinehart and Knight } \\
\text { (2004), Yager (1998) }\end{array}$ \\
\hline $\begin{array}{l}\text { 19. A host family will teach me about their } \\
\text { country's culture. }\end{array}$ & $\begin{array}{ll}- & \text { PE, IC, FS } \\
\text { - } & \text { Campbell (2004), Crealock (1999), Fryer and } \\
\text { Lukasevich (1998), Gutel (2007), Hansel (2007), } \\
\text { Kaplan (1989), Schmidt-Rinehart and Knight } \\
\text { (2004), Wilkinson (1998a), Woodall (1999), } \\
\text { Yager (1998) } \\
\end{array}$ \\
\hline $\begin{array}{l}\text { 20. The best homestay program will give } \\
\text { me a thorough orientation about living with } \\
\text { a host family. }\end{array}$ & $\begin{array}{ll}- & \text { PE, IC, FS } \\
\text { - } & \text { Campbell (2004), Crealock (1999), Fryer and } \\
& \text { Lukasevich (1998), Rivers (1998), Schmidt- } \\
& \text { Rinehart and Knight (2004) } \\
\end{array}$ \\
\hline $\begin{array}{l}\text { 21. I will learn more about the country's } \\
\text { culture if I live with a host family. }\end{array}$ & $\begin{array}{ll} & \text { PE, IC, FS } \\
\text { - } & \text { Campbell (2004), Crealock (1999), Fryer and } \\
& \text { Lukasevich (1998), Gutel (2007), Hansel (2007), } \\
& \text { Kaplan (1989), Schmidt-Rinehart and Knight } \\
& \text { (2004), Wilkinson (1998a), Woodall (1999), }\end{array}$ \\
\hline
\end{tabular}




\begin{tabular}{|c|c|}
\hline & Yager (1998) \\
\hline $\begin{array}{l}\text { 22. I will practice the language more living } \\
\text { with a host family than in a dormitory. }\end{array}$ & $\begin{array}{ll}- & \text { PE, IC } \\
\text { - } & \text { Campbell (2004), Crealock (1999), Hansel } \\
& \text { (2007), Iino (2006), Kaplan (1989), Rivers } \\
\text { (1998), Schmidt-Rinehart and Knight (2004), } \\
\text { Schmidt-Rinehart and Knight (2010), Tanaka } \\
\text { (2007), Wilkinson (1998a), Wilkinson (2002), } \\
\text { Woodall (1999), Yager (1998) }\end{array}$ \\
\hline $\begin{array}{l}\text { 23. Living with a host family will improve } \\
\text { my pronunciation. }\end{array}$ & $\begin{array}{ll}- & \text { PE, IC } \\
\text { - } & \text { Freed (1998), Ife (2000), Iino (2006), Tanaka } \\
\text { (2007), Wilkinson (1998a), Woodall (2002), } \\
\text { Yager (1998) }\end{array}$ \\
\hline $\begin{array}{l}\text { 24. My host family should treat me like one } \\
\text { of their own children. }\end{array}$ & $\begin{array}{ll}- & \text { PE, IC, FS } \\
\text { - Campbell (2004), Crealock (1999), ), Fryer and } \\
\text { Lukasevich (1998), Gutel (2007), Hansel (2007), } \\
\text { Iino (2006), Schmidt-Rinehart and Knight } \\
\text { (2004), Wilkinson (1998a) } \\
\end{array}$ \\
\hline $\begin{array}{l}\text { 25. I cannot tell my host family if I am } \\
\text { unhappy. }\end{array}$ & $\begin{array}{ll}\text { - } & \text { PE, IC, FS } \\
\text { - Campbell (2004), Crealock (1999), ), Fryer and } \\
\text { Lukasevich (1998), Gutel (2007), Iino (2006), } \\
\text { Schmidt-Rinehart and Knight (2004) }\end{array}$ \\
\hline $\begin{array}{l}\text { 26. My host family should give me a key to } \\
\text { their house. }\end{array}$ & $\begin{array}{ll}- & \text { PE, IC, FS } \\
- & \text { Gutel (2007) }\end{array}$ \\
\hline $\begin{array}{l}\text { 27. My host family should not tell me what } \\
\text { time to come home each night. }\end{array}$ & $\begin{array}{ll}- & \text { PE, IC, FS } \\
\text { - } & \text { Gutel (2007) } \\
\end{array}$ \\
\hline $\begin{array}{l}\text { 28. It is okay if there is more than one } \\
\text { student living with my host family as long } \\
\text { as we do not speak the same native } \\
\text { language. }\end{array}$ & $\begin{array}{ll} & \text { IC, FS } \\
\text { - Churchill (2003), Fryer and Lukasevich (1998), } \\
\text { Gutel (2007), Schmidt-Rinehart and Knight } \\
\text { (2004) }\end{array}$ \\
\hline
\end{tabular}

Note. $\mathrm{PE}=$ Personal Experience, $\mathrm{IC}=$ Informal Conversations with Current Language Students, FS = Interviews with Applied Linguistics Faculty or Faculty/Staff in the IELP at PSU

In addition to the quantitative section of the questionnaire, I also created a qualitative section consisting of six open-ended items. These items were designed to investigate student beliefs about homestays from a different angle than the quantitative items and to allow for students to respond in their own words. Gathering both quantitative and qualitative data targeting the same phenomenon (student beliefs about homestays) makes this a mixed methods study and allows for triangulation of those data. 
Triangulation of two different types of data increases the validity of a study by allowing for comparisons between the data (Ivankova \& Creswell, 2009), resulting either in confirmation of the results with similar findings from each data set, or exposing contrasts in the findings from each data set (pointing either to an invalid instrument or to a complex phenomenon that requires further, fine-tuned investigation).

\section{Reliability}

Because 25 minutes is a large amount of time to take out of a class period, some instructors preferred that students take the questionnaires home to complete instead of completing them in class. Although this affected the reliability of the study by giving some students a longer time to complete the questionnaire than those who completed them during class, the probability of recruiting a larger number of participates was seen as more beneficial than ensuring that all students take no more than 20 minutes to complete the questionnaire. Since the answers to the questionnaire are all subjective, it is unlikely that the longer amount of time available affected the students' answers (as would be the case if, for example, the questions were of the sort where a longer amount of time and no supervision would allow them to seek answers from reference materials).

To raise the reliability of the survey, two types of data were collected. In addition to the Likert-scale quantitative items, I constructed six open-ended items to gather qualitative data from the students. These data were used to augment each other during the analysis and interpretation of the results.

Multiple items were constructed for each of the seven categories in the 
questionnaire (see Table 2) in order to form multi-item scales. Multi-item scales raise the reliability of a questionnaire by using several items to target the same underlying theme or construct. The scores of the items in each scale are summed to provide an overall score for the scale that should average out inconsistencies arising purely from the wording of any one item in the scale (D $\square$ rnyei, 2007). In some categories, some items were reverse coded to further check for reliability (see Table 4). By including some negative statements as reverse coded items, the researcher can look out for the possibility of a respondent simply circling all of the 4's on a questionnaire, for example (D $\square$ rnyei, 2003). The order of the items was determined by using an online random number generator so that questions from different scales were mixed together. This process serves to reduce monotony and possible boredom in the respondents and reduces the chance that the respondents will simply circle the same number for each item (D $\square$ rnyei, 2007).

Table 4

Examples of Reverse-Coded Items

\begin{tabular}{|l|l|}
\hline \multicolumn{1}{|c|}{ Category Polarization } & \multicolumn{1}{c|}{ Example of Reverse-coded Item } \\
\hline $\begin{array}{l}\text { Multiple Boarders: higher score indicates multiple } \\
\text { boarders are seen as a good thing }\end{array}$ & $\begin{array}{l}\text { 16. It is best if I am the only student living } \\
\text { with my host family. }\end{array}$ \\
\hline $\begin{array}{l}\text { Dependence on Host Family: higher score indicates } \\
\text { less dependence }\end{array}$ & $\begin{array}{l}\text { 24. My host family should treat me like one } \\
\text { of their own children. }\end{array}$ \\
\hline $\begin{array}{l}\text { Open Communication: higher score indicates } \\
\text { students can talk openly with their host family }\end{array}$ & $\begin{array}{l}\text { 25. I cannot tell my host family if I am } \\
\text { unhappy. }\end{array}$ \\
\hline
\end{tabular}




\section{Questionnaire: Pilot Testing}

The questionnaire was pilot tested in two IELP classes to ensure that the items were worded as unambiguously as possible. As a result of pilot testing, the format of the original questionnaire was changed to allow for a larger and more easily readable font for the Likert-scale items and some words the students were not familiar with were clarified with parenthetical explanations or replaced by a simpler phrase. Students identified words they did not understand by circling them while taking the questionnaire. As a result the words "demographics" and "chores" were clarified in parentheses and the word "curfew" was replaced by the phrase "what time to come home each night."

\section{Data Collection Procedures}

The questionnaire was administered to students in one of two ways, depending on the instructors' preference. The first method of delivering the questionnaire was during class, with the instructors' permission. The questionnaire usually took no more than 25 minutes to complete, including the explanation of the research and the signing of consent forms. I personally attended every class in order to explain the purpose and possible benefits of the study to the students and to ask for their participation. Since the questionnaires were administered within a class period, I personally distributed and collected them in the classes that I attended. Questionnaires were administered to five classes in this way.

If class instructors could not allow the questionnaires to be administered during class, I visited their class for 5 minutes to explain the project and distribute consent forms 
and questionnaires to the students asking for their participation. Students who chose to participate completed the questionnaires at home and returned them to their instructors during the next few class periods, after which I picked them up from the instructors. Questionnaires were distributed in five classes in this way.

There were two cases outside of the above methods. In one case, the instructor printed and distributed the surveys and I brought and distributed the consent forms in class. In one other case, because of a time conflict, I could not personally visit the class; the instructor printed and distributed both the consent forms and questionnaires. In both cases the instructors stressed that the questionnaire was optional and anonymous and was not connected to their own research or the students' standing within their class or the university in any way.

\section{Data Analysis Procedures}

I analyzed the quantitative data by first computing the mean and standard deviation for the responses to each of the Likert-scale items $(n=116)$. I then computed the mean and standard deviation for the seven categories in the questionnaire by summing up the responses of the four items in that category and calculating the mean. The responses to the reverse-coded items were reversed when combining them with the other items in their categories.

For the comparison of the three groups, I first deleted the students that had missing data so that the comparisons could be done on students who had responded to all of the Likert-scale items. There were 39 students in the Homestay group (have done or 
are currently in a homestay), 38 students in the Future Homestay group (have not done a homestay but intend to), and 31 students in the No Homestay group (have not done a homestay and do not intend to) for a total of 108 students. I calculated the mean and standard deviation for each group in the same way as they were calculated for the entire sample.

For the qualitative data provided by the students in answer to the six open-ended questions in Part 3 of the questionnaire, I first transcribed the responses for each question into a word document (one document per item). During this transcription process, the students' group identifier (indicating whether the student was in the homestay, future homestay, or no homestay group) was removed from their responses so that knowledge of their group would not influence the coding.

Once I completed the transcription, I coded the responses according to the following process. First, as I read through a file of responses to a question, I jotted down themes that seemed to come up often. For example, when several participants mentioned the ability to learn about the culture as something beneficial about homestays, I wrote down "CUL" as a possible theme for that item. In this manner, I created a preliminary list of themes for each of the six items. I then looked at the themes to see if any were closely related or if any of them could actually be contained as a sub-theme of a larger overall theme. This allowed me to create a list of codes that corresponded to the themes that I had found while reading through the data the first time.

After I had a preliminary list of codes for the responses, I read through the files 
again, assigning a code to each response. Some responses contained multiple phrases or sentences, each falling into a separate code. For example, a respondent might have made reference to both language practice and a family support system when responding what they thought was helpful about homestays. If I came across responses that did not seem to fit into any of the codes I had begun with, I made a note to adjust the scope of the existing codes or possibly add another code to the list if other students' responses were similar. This type of data analysis can be visualized as a sort of spiral; the researcher begins with the data and makes some broad codes, then circles and focuses in on the data to assign those codes. In the process, other themes may become apparent, necessitating another round of code making and assignment, and so forth (Creswell, 2006).

There were also some cases where a response had to be excluded from the analysis, either because it appeared that the student had misunderstood the question, or because the response was too vague for me to be able to confidently decide on a theme for it. These types of responses were rare. After I had finished the preliminary coding of the data, I revisited the coding framework to see how I could integrate the responses that had been difficult to code with the preliminary framework. At this point I collapsed some codes that seemed to be very similar into one larger code. In rare instances, I split what I had originally labeled as one code into two separate codes to show that responses that had at first appeared similar seemed to be falling into separate, distinct themes after all. After adjusting the framework to account for those responses, I went through the data files again, making changes to the preliminary codes I had assigned if necessary so that the 
responses would all reflect the updated framework and using the newly created codes for the responses that had not fit in the preliminary framework. Once all of the responses were coded, I counted the number of times each code occurred, resulting in the totals for the themes and number of coded segments in each theme that I refer to in the discussion of the open-ended items. 


\section{Results and Discussion: Research Question \#1}

The first research question in this study was, "What are the beliefs that students studying a foreign language have about homestays?" The results from the questionnaires are presented and discussed in this section.

\section{Responses to Likert-Scale Items}

The results of the Likert-scale items are presented in Table 5. For each item, the mean and standard deviation are reported. The questionnaire was a 5-point Likert-scale, so the lowest possible score was 1.0 and the highest possible score was 5.0.

\section{Table 5}

Results of Likert-scale Items

\begin{tabular}{|l|c|c|}
\hline \multicolumn{1}{|c|}{ Item } & Mean & $\begin{array}{c}\text { Standard } \\
\text { Deviation }\end{array}$ \\
\hline $\begin{array}{l}\text { 1. A host family will help me make friends with native speakers of the } \\
\text { language I am studying. }\end{array}$ & 3.91 & .97 \\
\hline 2. Living with a host family is the best way to experience a new culture. & 4.20 & .85 \\
\hline $\begin{array}{l}\text { 3. I will meet more native speakers of the language I am studying if I live } \\
\text { with a host family than if I live in a dormitory. }\end{array}$ & 3.77 & 1.25 \\
\hline $\begin{array}{l}\text { 4. My host family should not expect me to do chores (for example: wash } \\
\text { dishes, do laundry, watch children, clean the house). }\end{array}$ & 2.70 & 1.19 \\
\hline $\begin{array}{l}\text { 5. If more than one student lives with my host family, we will not be able } \\
\text { to learn the language we are studying well. }\end{array}$ & 2.94 & .80 \\
\hline 6. If I have any problems, the homestay program will help me. & 3.78 & .76 \\
\hline $\begin{array}{l}\text { 7. If there is more than one student living with my host family we can } \\
\text { spend time together. }\end{array}$ & 3.77 & 1.07 \\
\hline 8. It is rude to ask my host family to change something for me. & 2.93 & .87 \\
\hline $\begin{array}{l}\text { 9. The homestay program should let me communicate with my host family } \\
\text { before I leave my country. }\end{array}$ & 4.13 & 1.04 \\
\hline $\begin{array}{l}\text { 10. I will spend more time with people from my own country if I live in a } \\
\text { dormitory. }\end{array}$ & 3.68 & .79 \\
\hline 11. A host family will introduce me to their friends and family. & 3.99 & .90 \\
\hline 12. I can trust a homestay program to find a good host family for me. & 3.49 & .91 \\
\hline 13. If I disagree with my host family, I can tell them. & 3.81 & 1.08 \\
\hline 14. Living with a host family will improve my grammar. & 2.76 & 1.06 \\
\hline 15. Even if I don't like my host family's food, I can't tell them. & 3.59 & \\
\hline 16. It is best if I am the only student living with my host family. & & \\
\hline
\end{tabular}




\begin{tabular}{|l|c|c|}
\hline $\begin{array}{l}\text { 17. Every student studying a foreign language abroad should live with a } \\
\text { host family. }\end{array}$ & 3.14 & 1.04 \\
\hline 18. I will not learn about the host country's culture if I live in a dormitory. & 2.73 & 1.13 \\
\hline 19. A host family will teach me about their country's culture. & 4.03 & .73 \\
\hline $\begin{array}{l}\text { 20. The best homestay program will give me a thorough orientation about } \\
\text { living with a host family. }\end{array}$ & 3.92 & .88 \\
\hline 21. I will learn more about the country's culture if I live with a host family. & 4.12 & .75 \\
\hline $\begin{array}{l}\text { 22. I will practice the language more living with a host family than in a } \\
\text { dormitory. }\end{array}$ & 4.08 & .94 \\
\hline 23. Living with a host family will improve my pronunciation. & 4.27 & .75 \\
\hline 24. My host family should treat me like one of their own children. & 3.20 & 1.13 \\
\hline 25. I cannot tell my host family if I am unhappy. & 2.34 & 1.00 \\
\hline 26. My host family should give me a key to their house. & 4.03 & .89 \\
\hline 27. My host family should not tell me what time to come home each night. & 3.36 & 1.20 \\
\hline $\begin{array}{l}\text { 28. It is okay if there is more than one student living with my host family } \\
\text { as long as we do not speak the same native language. }\end{array}$ & 3.43 & 1.17 \\
\hline
\end{tabular}

Table 6 presents the results of the Likert-scale items when they are grouped into the seven categories of the survey.

Table 6

Results of the Likert-scale Items Presented by Category

\begin{tabular}{|l|c|c|}
\hline \multicolumn{1}{|c|}{ Category } & Mean & $\begin{array}{c}\text { Standard } \\
\text { Deviation }\end{array}$ \\
\hline A. Homestays and Language Acquisition & 3.79 & 1.05 \\
\hline B. Homestay Program & 3.83 & .89 \\
\hline C. Culture & 3.77 & 1.07 \\
\hline D. Interaction with Native Speakers & 3.84 & .95 \\
\hline E. Multiple Boarders & 3.16 & 1.17 \\
\hline F. Dependence on Host Family & 3.37 & 1.20 \\
\hline G. Open Communication & 3.45 & 1.08 \\
\hline
\end{tabular}

The categorical results suggest that the students, overall, believed that a homestay would be helpful for language acquisition, that a homestay program should be involved in their homestay experience and provide assistance and services, that a homestay would be helpful for learning about the host culture, that a homestay would provide more 
interaction with native speakers than a dormitory, that having multiple boarders staying with one host family is only slightly beneficial, that they should not be too dependent on the host family, and that they should be able to communicate openly with their host family. However, since the means for these responses fell between the "Neither Disagree nor Agree" and "Agree" points on the scale and the standard deviations for all categories included scores that would fall into the position between "Disagree" and "Neither Disagree nor Agree", it cannot be said that these beliefs are held strongly by the majority of the students.

In the following discussion of the responses to the open-ended items, results from the Likert-scale items will be used to provide a more rounded view of the themes mentioned. Quotes from respondents are labeled with the respondent's questionnaire number (000-116) and group (Homestay Group = HG, Future Homestay Group = FHG, No Homestay Group = NHG).

\section{Responses to Open-Ended Items}

\section{Item \#1}

In the responses to Item \#1—“Do you think homestays are helpful for students studying a language in a foreign country? Why or why not?"- eight major themes became apparent. The two most common themes were that homestays are helpful to improve the student's language skills and that they are helpful to improve the student's cultural skills. Students mentioned the following areas of the language that homestays helped improve: vocabulary, conversation and listening/speaking skills, pronunciation, 
and knowledge of slang. They also mentioned that a homestay was an opportunity to practice what one learned in class and that it allowed one to interact with native speakers. The following examples illustrate the language theme (recall that some of the respondents were not native speakers of English; although spelling mistakes were corrected, errors in grammar were not):

Yes, as far as he/she practice speaking [the language]. Because he will use [the language] only to communicate. Also, he/she will learn new vocabulary and how to pronounce [words]. (Respondent \#013, FHG)

Yes, I do. Students can learn [the natural language] in their daily living, slang, etc... In school, we learn only academic [language]. (Respondent \#032, HG) Yes, it gives more time to practice the language with native speakers. (Respondent \#106, NHG)

In these ways, we can see that some students view the homestay as beneficial to their language acquisition. Of the 144 total coded segments in the responses to Item \#1, the theme of improving the language was mentioned 41 times.

It is interesting to note that the types of language skills mentioned cluster around conversation (listening, speaking, pronunciation) and vocabulary (including slang). Students did not mention that they believed a homestay would help them improve their reading, writing, or grammar skills. Thus, the beliefs of these students seem to align with the common view of a homestay that it is the vocal interaction with native speakers that a homestay affords that will improve the language skills of the student. In the Likert-scale 
responses in Category A, Homestays and Language Acquisition, the same beliefs are apparent. While students agreed fairly strongly that a homestay would improve pronunciation $($ mean $=4.27, \mathrm{SD}=.75)$ and give them more opportunity to practice the language $($ mean $=4.08, \mathrm{SD}=.94)$, they only slightly agreed that a homestay would improve their grammar $($ mean $=3.66, \mathrm{SD}=1.08)$.

Since students appear to believe that a homestay will improve their conversational skills, Rivers' (1998) findings from a study of homestay students in Russia that the homestay was a positive predictor of reading gain, not speaking or listening gain, are all the more striking. Students may be entering a homestay with the belief that their conversation skills will improve simply by being in close contact with native speakers, unaware that other factors such as the responsiveness of the host family members to the student or the amount of actual time spent in conversation and type of language used by native speakers to communicate with their homestay student, may come into play. Indeed, the students in Tanaka's (2007), Wilkinson's (1998a), and Woodall and Takeuchi's (1999) studies reported that they did not converse with their host families as often as they had anticipated, that some of their host families were not warm or welcoming to their students, resulting in the students' hesitation to initiate many conversations, or that their families, when they did speak, used simple language that was not challenging for the students and that they did not think would help them improve over time.

The second major theme, mentioned 29 times, was culture. Students indicated 
that a homestay would be helpful for students studying a language because they could learn more about the culture, customs, and traditions of the native speakers of that language. Some students mentioned that a homestay was particularly important because it gives a student a family-life perspective on the host culture.

Yes, because they allow a student to see first hand what a culture is like through the perspective of living with a family. (Respondent \#116, FHG)

Yes, you learn about the culture more with a host family. You're forced to eat their food, watch TV with them, and discuss what they like. (Respondent \#100, FHG)

Yes, if we come to learn and experience other country, we better live in a host family. (Respondent \#062, HG)

I do. I think it is the most accurate/original way to experience a new culture, that is, to experience the family dynamics of one. (Respondent \#90, FHG)

These statements reveal that many students believe the family aspect of a homestay to be helpful for learning about the culture of their host country. However, a student's idea of a "family" may be different from the actual placement they receive. For example, in the United States, a host family may consist of a heterosexual couple and small children or teenagers, but it may also consist of a single man or woman, an elderly couple, or a homosexual couple (with or without children). Alternatively, a host family may consist of people who have immigrated from another country and retained their country's cultural values, or they may be second or third generation descendants of immigrants. If 
the host family members themselves are immigrants, they may not even be native speakers of English.

It is not clear from the student responses whether or not they take these considerations into account when they think about homestays. Granted, some of the students who participated are American students, and thus are thinking of a homestay in the context of a country different from the United States, which may not have these types of population dynamics. However, other students who participated in the questionnaire are students who have come from other countries to study English in the United States. Among all of the culture/family themed responses, there was only one that mentioned any of these issues:

Kind of. If the homestay is a native speaker. For example, my homestay family is from other country, so... (Respondent \#002, HG)

If a student believes that a homestay will be beneficial because it will provide them with an inside look at the culture or family-life of people in another country, it is necessary to look further into what type of "family" they envision. If a student has a prototypical family or cultural unit in mind when they think of the benefits of a homestay, their perception of the homestay experience may be adversely affected if the family they are placed with does not match their original image.

One student did mention that caution must be taken with regards to the language and culture of one's specific family, but this was not in reference to the make-up of the family. 
Possibly. There's a risk of assuming that the cultural practices of a host family are universal when they might not be, same with dialect. (Respondent \#083, NHG)

Rather than a problem arising with a host family because it is not what the student had expected, this participant points out that the host family is only one family out of an entire cultural or linguistic group. Although a student may indeed receive an inside look into culture and family-life, this participant cautions that generalizing from that inside look may be a mistake.

This caution is not apparent in any of the other responses, which instead seem to value the homestay precisely because they will gain deeper cultural knowledge and knowledge of family-life. It seems that most of the students consider this increase in cultural knowledge beneficial for the express purpose of applying it to the culture of the host country at large. Indeed, many students agreed with the items in the Likert-scale section that stated that a homestay is the best way to learn the culture (mean $=4.20, \mathrm{SD}=$ $.85)$, that the host family will teach the student about the culture (mean $=4.03, \mathrm{SD}=.73$, and that they will learn more about the culture by living with a host family (mean $=4.12$, $\mathrm{SD}=.75)$

Closely related to both the language and cultural themes was the theme of total immersion (occurring 20 times). Students who responded that homestays were beneficial because they offered a complete immersion experience often mentioned both the language and culture together. This theme also includes responses that indicate 
homestays are helpful because the student will be forced to use the language being studied every day.

Yes, they are helpful because you will need to speak only the ... language.

(Respondent \#020, HG)

Yes, I think it is a great way to fully immerse yourself in the language and culture.

(Respondent \#033, NHG)

The remaining 5 themes were not as prevalent as the first 3 , but they offer extra insights into the beliefs that student have about the benefits of homestays. Two of them, the themes of receiving support and having teachers, relate specifically to the host family. In the theme of receiving support, students mentioned services that the host family would provide them with in regards to living in a new country, such as help adjusting, taking care of the student, and giving a sense of safety. The theme of having teachers related to the responses in which students indicated that a host family will take the initiative to talk to the student and actively help them improve their language. Examples of these themes follow:

I think homestays are helpful for giving the student a safe place to stay.

(Respondent \#101, FHG)

Yes. In an ideal situation the host family would help the student improve on the language while introducing the student to a new culture. (Respondent \#113, NHG)

Yes, because they will help for homeworks and we will improve our [language]. 
(Respondent \#069, NHG)

The belief that the host family will take on the role of a language teacher appears to be held by many students (see Wilkinson, 2002) but it may not always be realized in actual homestay situations. Although common sense might indicate that native speakers of a language decide to host foreign students with the knowledge that the student will most likely expect them to assist them in learning the language, this may not always be the case; some host families may decide to host students for purely monetary reasons. Other host families may attempt to aid their students but use foreigner talk and modify their speech such that the student does not make gains in their language acquisition (Tanaka, 2007). The belief that the host families will take an active role in teaching the language thus may lead students who are placed in families where this does not occur to perceive their experience in a negative light.

Another theme related to language use that emerged was that of being able to learn how to use the language in real, daily life. Rather than mentioning an increase in language skills in general, these students noted that homestays are helpful because you can learn language necessary for daily life that you may not learn in a classroom or dormitory.

Yes, because many words and situations in the daily life can't be learned in the class. (Respondent \#004, NHG)

They allow a real-life learning situation of the language. (Respondent \#071, HG) While most students mentioned various specific aspects such as language 
acquisition, culture, immersion, support, teachers, and real-life language as reasons that they believe homestays to be helpful, some students simply responded in a general, vague sense that they felt homestays were beneficial, as in the following examples:

I think homestays are very help for abroad students because the student can learn from them many things. (Respondent \#010, HG)

Yes, because if I feel comfortable with the host family, I'm going to learn a lot from them. (Respondent \#053, NHG)

Finally, some respondents answered that they either did not think a homestay would be helpful or that they thought a homestay would be helpful only in certain situations. There were 13 segments in this theme. Some of these students mentioned concrete reasons that they believed a homestay would not be beneficial, while others were more vague in their responses. Many students in this category responded that a homestay would be helpful only if the host family cared for the student.

In some host families yes, but there are horrible host families and they treat you such as an animal. It depends, and also there are a host families who steal your personal stuff. (Respondent \#046, HG)

No. Friends is best. (Respondent \#038, FHG)

Depends on homestays. Some of them are willing to spend time to help students; however, some of them are busy with their career or other things, so they are not able to do that much for the students. (Respondent \#066, HG)

From these responses, we can see that not all students believe a homestay to be helpful 
for students in every situation. There may be homestays where the host family is not very attentive to the student, or where the host family may even intentionally treat the student poorly. However, the majority of students responded that a homestay is helpful in some way. Their responses do not indicate that they are completely unaware of the possible drawbacks of poor homestays; rather, they simply indicate that, even if the majority of students are aware of the potential drawbacks, their overall beliefs about the helpfulness of homestays for language learning were still positive.

From these eight categories, it can be seen that, although some students did respond that homestays were not always helpful, the majority of students responded that they believed homestays to be helpful for students studying a language in a foreign country. The benefits mentioned most often were related to various aspects of language and culture, but there were also some benefits mentioned related to support for living in a foreign country. Table 7 summarizes the results for Item \#1. In this table and those following in the discussions of each of the open-ended items, "segment" refers to the sentence or phrase that the participant wrote that was coded into a particular theme. A participant may have written several sentences or phrases that each fell into a different theme or may have left an item blank; thus the total number of segments coded may be larger or smaller than 116 , the number of participants in the study.

\section{Table 7}

Item \#1 Results 


\begin{tabular}{|l|c|}
\hline \multicolumn{1}{|c|}{$\begin{array}{c}\text { Themes } \\
\text { (Question: Is a homestay helpful?) }\end{array}$} & $\begin{array}{c}\text { Number of Segments in } \\
\text { Theme }\end{array}$ \\
\hline 1. Yes, helpful for language acquisition & 41 \\
\hline 2. Yes, helpful to learn about culture & 29 \\
\hline 3. Yes, gives a full immersion experience & 20 \\
\hline 4. Yes, host family will teach the student the language & 13 \\
\hline 5. No & 13 \\
\hline 6. Yes, gives support for living in a foreign country & 10 \\
\hline 7. Yes, gives exposure to daily, real-life language use & 10 \\
\hline 8. Yes, in general & 8 \\
\hline Total: & $\mathbf{1 4 4}$ \\
\hline
\end{tabular}

\section{Item \#2}

While the first item inquired whether students believed a homestay was helpful for learning a foreign language or not, the second item sought to investigate whether students believed a homestay was necessary or not: "Do you think living with a host family is necessary to learn a foreign language? Why or why not?"

The responses to this item, like the responses to the first item, were varied. There were three overarching themes that occurred, each with their own subgroups. The most common theme, accounting for 86 of the 129 coded segments, was that students did not believe a homestay was necessary to learn a foreign language. Almost half of these students stated that a homestay was good, optimal, or otherwise beneficial for learning a foreign language or culture, but they would not go so far as to say it was necessary.

No. It will improve my language and its helpful, but I shouldn't call it necessary. 
(Respondent \#016, FHG)

Not necessary, but it's a good chance to learn foreign culture. (Respondent \#051, HG)

Other students in this group rejected the idea that homestay was necessary by mentioning many other ways that a student could learn a language including, for example, watching movies or television, going to cafes or the gym, making friends with native speakers, taking language classes, or studying by oneself. The following are some examples of these responses:

No, only a way to do it, not the only way. (Respondent \#033, NHG)

No, because you can make friends on campus and you can improve your [language skills] with them. (Respondent \#049, NHG)

No, living with a host family is a good way to learn a foreign language. But by attending public activities, chatting with native people, attend class in school, also can help me learn language. (Respondent \#005, NGH)

Thus many of the students believe that homestays are simply one useful tool or method for learning a language, among other methods. While half of these students view homestays as the ideal, best, or optimal method to use, the other half seem to place a homestay on equal footing with other activities such as taking classes or making friends with native-speaking students on campus, in cafes, or in the gym.

Although those two subgroups, the "not necessary but beneficial" group and the "there are many ways to learn a language" group, accounted for the majority of segments 
in the overall theme of a homestay not being necessary, there were also some students who did not believe that a homestay was necessary because a truly motivated language student would be able to learn a language regardless of their circumstances. For example, one student responded

No, if one is willing to emerge themselves into a culture and attempt to converse with the people then one can learn. All it takes is determination. (Respondent \#084, FHG)

A particularly interesting response in this category serves to showcase the belief that these students appear to have that anything will be possible for the student who puts their mind to it:

In my opinion, $\mathrm{NO}$, because if you want to learn you will learn even if you're living in a alley or a bridge. (Respondent \#029, NHG)

Responses such as these two seem to indicate that students believe learners to be able to immerse themselves into a foreign culture without living with a host family, as long as they try hard enough. It is not clear whether the students who believe in the strength of a learner's motivation are aware of the many potential difficulties one might encounter while trying to immerse oneself in a foreign culture.

It is often difficult for international students on a college campus to approach native-speaking students and form friendships. Although many universities provide conversation partners or some other sort of language or culture exchange activities, international students may not always find native-speaking students ready to dive into 
deep friendships and act as a guide or help to immerse them in the culture of the host country. Trying to immerse oneself in culture by going to a gym, going shopping, or attempting to strike up conversations with strangers in cafes are all strategies that may appear on the surface to be easier and more successful than they may actually turn out to be.

The responses to the Likert-scale items in Category D: Interaction with Native Speakers, agree with the views stated in this theme. While students did agree that a host family would help them make friends with native speakers $($ mean $=3.91, \mathrm{SD}=.97)$ and introduce them to friends and family (mean $=3.99, \mathrm{SD}=.79$ ), and that they would meet more native speakers if they lived with a host family than in a dormitory (mean $=3.77$, $\mathrm{SD}=.97)$ and spend more time with people from their own country if they live in a dormitory $($ mean $=3.68, \mathrm{SD}=1.04)$, none of the means of these responses fell between "Agree" and "Strongly Agree". Thus it can also be seen from these results that the students did not seem to believe that it would be particularly difficult to interact with native speakers even if they did not live in a homestay.

Students in several studies have reported that they did not become as immersed in the culture as they had anticipated even while staying with a host family (River, 1998; Tanaka, 2007; Wilkinson, 1998a; Woodall \& Takeuchi, 1999). Many of these students reported choosing a homestay for the language and culture immersion, but when their homestays - for various reasons - did not prove to be the experiences they had anticipated they often ended up spending time with classmates who shared their native 
language. Since even students who have participated in homestays have reported that they found it difficult to integrate themselves into the culture of their host country, students who are not living with a host family may find it more difficult than they may at first imagine to immerse themselves in the host country culture. Students have found it difficult to become immersed in the culture even with a host family as a guide or role model; without the benefit of a host family students living in a dormitory or an apartment may find it even more difficult.. Indeed, one participant who believed that a homestay was necessary voiced these very concerns:

Yes! Because it forces you to communicate needs in the language of study, if living in a dorm, there are more people/resources that speak your native language and the temptation to cheat is more prevalent. (Respondent \#093, FHG) The final subgroup that indicated that a homestay was not necessary to learn a language mentioned that staying with a host family will not always be optimal for a student. For example, the host family may not care about their student, the student may choose to simply stay in their own room, or the student may be put under stress from living with strangers. Because of these possibilities, a homestay was not believed to be necessary to learn a foreign language.

No, I don't. Some people may feel stress even though a host family is so kind. (Respondent \#040, HG)

It's not necessary but ideal. Some people might feel uncomfortable living with a host family and it will reflect in learning. (Respondent \#092, FHG) 
The counterintuitive findings from Rivers' (1998) study that a homestay was a positive predictor for reading, not speaking or listening gain, are related to this belief. Rivers found that many of the students spent more time in their rooms studying alone than interacting with their host families.

The second overarching theme, although far less common than the first, was the theme that yes, a homestay is necessary to learn a language. There were 28 segments coded in this theme, broken into three subgroups. One group consisted of four segments which simply stated in general terms that a homestay was necessary. The other two subgroups, occurring 14 and 10 times respectively, were that a homestay is necessary for language learning and that a homestay is necessary for culture learning. Some examples of these types of responses follow:

Yes, because they can teach you more than just the language, they can also teach the culture. (Respondent \# 081, FHG)

Yes. At least one year experience. Reason: It is easy to know about the culture and you can practice the language skill with the host family most at the time. (Respondent \# 009, HG)

Yes. To integrate in community. (Respondent \#025, HG)

I extremely agree. Students will practice [the language] every day in many way. It will improve the listening and speaking. It will let them know more about the country culture. (Respondent \#035, HG)

The third and final overarching theme was that whether or not a homestay is 
necessary to learn a foreign language depends on either the student or the host familybut most of the responses focused on the student. Many were some variation of the following:

No. It depends on the person. (Respondent \#039, FHG)

These responses, although not specifically mentioning motivation, seem to be related to the theme that a motivated student can learn in any situation. A homestay may be necessary for some people to learn a language, these students believe, but others may be able to learn without staying with a host family.

Although the majority of the responses to Item \#1 showed that the students generally believed homestays to be beneficial, the responses to Item \#2 have shown that, while beneficial, a homestay is generally not believed to be necessary for learning a foreign language. Table 8 summarizes the results for Item $\# 2$.

Table 8

Item \#2 Results

\begin{tabular}{|l|c|}
\hline \multicolumn{1}{|c|}{$\begin{array}{c}\text { Themes } \\
\text { (Question: Is a homestay necessary for language } \\
\text { acquisition?) }\end{array}$} & $\begin{array}{c}\text { Number of Segments in } \\
\text { Theme }\end{array}$ \\
\hline $\begin{array}{c}\text { 1. No } \\
\text { - No, but good/optimal/helpful } \\
\text { - No, there are many ways to learn a language } \\
\text { No, motivated students will learn in any } \\
\text { circumstances }\end{array}$ & 86 \\
\hline No, host families may not be helpful & \\
\hline 2. Yes, for language and/or culture & 28 \\
\hline
\end{tabular}




\section{Total:}

\section{9}

\section{Item \#3}

Items \#1 and \#2 investigated students' beliefs about homestays in general, asking students to reflect specifically on their beliefs about the homestay as beneficial to or necessary for language learning. Items \#3 and \#4, however, went beyond students' general beliefs about homestays to investigate specifically what they believe to be the best (Item \#3) and worst (Item \#4) things about homestays, with no overt tie to language learning mentioned in the questions.

Four main themes arose in the responses to Item \#3 (the best thing about homestays). The most frequent theme, occurring in 59 out of 153 coded segments, was that of immersion into the culture. Students mentioned that the immersion offered by a homestay gave them a look at the regular, daily life of their host families so that they could learn more about the culture than was mentioned in textbooks. They also mentioned that homestays would allow them to learn new things.

To learn the real local culture. (Respondent \#003, HG)

The best thing is to know the other country. (Respondent \#057, HG)

It's culture immersion as well as language immersion, so the depth of the experience goes much further than the classroom. (Respondent \#073, FHG) A small number of students in this group expressed the belief that living in a homestay would give them an advantage with regards to the types of activities that they could do 
while staying in the foreign country. Some stated that their host family could take them places and showcase the host country and culture in ways that international students living in a dorm trying to explore on their own, without native guides, would not be able to experience.

Having a family that will help you adapt to the culture faster \& who will do things with you \& go places that you wouldn't get to do any other way or on your own. (Respondent \#086, HG)

You see more of the city. I think it would be harder on your own when not knowing the language very well. (Respondent \#099, FHG)

The quantitative data, as mentioned in the discussion of Item \#1, also show that the students generally agreed that a homestay would allow them to learn about the host culture $($ mean $=3.77, \mathrm{SD}=1.07)$.

Following the theme of immersion into the culture were the themes of language improvement (40 segments) and having the support of a family setting (39 segments). Many students responded that the best thing about a homestay is the opportunity to practice and improve in the language they are studying, as in the following examples:

You will learn the language better and faster. (Respondent \#027, NHG) You can practice [the language] after school. (Respondent \#037, FHG) Your learning would accelerate, I'd think, because of how many different aspects of the culture/language you absorb. (Respondent \#080, NHG) A subset of the respondents in the language improvement theme specifically mentioned 
learning to communicate better in the language they were studying as the best thing about living in a homestay.

Your practice in communication. (Respondent \#007, HG)

The best thing is to communicate with each other. (Respondent \#040, HG) Again, as mentioned in the discussion of Item \#1, students generally agreed that a homestay would benefit their acquisition of the foreign language (mean $=3.79, \mathrm{SD}=$ $1.05)$.

The third theme in response to Item \#3, the theme of having the support of a family setting, had several subthemes. Students mentioned not having to be lonely, having an international family, making lifelong friends with members of the host family, having native speakers/members of the host culture to ask for help if something went wrong, and having a safe, comfortable place to stay in their responses to Item \#3.

To meet nice family who are generous, faithful and warm-minded. (Respondent $\# 012, \mathrm{NHG})$

In the best situation you would be able to feel at home away from home. (Respondent \#077, NHG)

Host families often take the student on trips that display their country's culture, values, etc. These trips create everlasting memories and bonds between the host family and the student. (Respondent \#097, HG)

That you have people to fall back on for advice or questions, people who have been there their whole life. (Respondent \#105, NHG) 
That these aspects of a homestay were listed as the best things about homestays shows that these students seem to believe a host family will function much like an ideal biological family might: offer friendship and advice, create a comfortable and safe living environment, and take part in lasting friendships.

Thus, the three top themes for the best thing about homestays all contained some sort of interpersonal interactions. Students who mentioned cultural immersion saw the value of the homestay lying chiefly in the knowledge and experience about the host country's culture that they could gain while interacting with natives of that culture in daily life, while students who mentioned language improvement saw the value of the homestay lying in the ability to practice the language and communicate daily with native speakers. Finally, students who mentioned the support of the family environment saw the value of the homestay lying in the friendships and network of support that could be formed by living with a family.

The fourth theme for Item \#3, however, did not contain interpersonal interactions as a component; rather, it focused on the convenience of the homestay. The theme of convenience was notably less frequent than the other three themes (occurring in only 10 segments). The convenient aspects of a homestay mentioned by participants included the proximity of the dwelling place to the school, the lack of chores or bills for students to worry about, the fact that the host family provides meals for the student, and the cheap price of the homestay.

If the house closed to the school, homestays will be the best choose. I don't need 
to cook and wash clothes. (Respondent \#002, HG)

Don't need to cook. (Respondent \#008, HG)

You don't need to worry about too many things about the house. Mostly you just take care of your own room and help with some of chore sometimes. (Respondent \#066, HG)

It may seem that the host family members are expected to take care of most facets of daily life by students who view these assets as the best things about a homestay. Indeed, one student responded to Item \#3 with the following:

The homestay is best for students that depends on others in every thing. (Respondent \#028, NHG)

The prevailing image of the homestay among these respondents seems to be that of a useful tool rather than as a vessel through which they can have access to meaningful interactions with native speakers, such as was apparent in the first three themes. This is, however, a list of responses to the question of the best thing about homestays; if students had been told to list several good things about homestays those who fell into one of the first three themes might have also listed items in the convenience theme, and those who listed convenience first might have also recognized the more interpersonal aspects of a homestay in a longer list.

However, since it is not a given that the host family will expect no help with chores from their exchange students or that the host family will prepare every meal for their students, etc., students who enter a host family prioritizing these aspects may 
encounter difficulties when they realize that they are expected to participate in these daily chores. Students who prioritized the interpersonal aspects of the homestay, on the other hand, may be better equipped to adjust their beliefs about their role in the chore schedule of their host family if the host family's expectations differ from theirs.

It is interesting to note that cultural immersion was mentioned most often as the best thing about a homestay as opposed to language improvement. This may be due to the fact that the majority of the students do not believe a homestay to be necessary for language acquisition (Item \#2). Since a homestay is not seen as necessary for language learning (a dormitory or apartment in the host country would suffice), it is plausible that the highest value of the homestay would then be something that one of those other living situations would not afford: namely, the inside view into the daily life and culture of a family. Table 9 summarizes the results of Item \#3.

Table 9

Item \#3 Results

\begin{tabular}{|l|c|}
\hline \multicolumn{1}{|c|}{$\begin{array}{c}\text { Themes } \\
\text { (Question: What is best about homestays?) }\end{array}$} & $\begin{array}{c}\text { Number of Segments in } \\
\text { Theme }\end{array}$ \\
\hline 1. Cultural immersion & 59 \\
\hline 2. Language improvement & 40 \\
\hline 3. Support of a family setting & 39 \\
\hline 4. Convenience & 10 \\
\hline Total: & $\mathbf{1 5 3}$ \\
\hline
\end{tabular}

\section{Item \#4}


In Item \#4, students were asked what they thought the worst thing about homestays was. In contrast to Item \#3, where only four major themes appeared, 10 themes were found among the responses to Item \#4. However, the number of segments in each theme was smaller. The four most common themes had 15-26 segments, while the other six themes had five segments (three themes) or seven segments (three themes).

The most commonly mentioned theme was a lack of being treated as an adult or given freedom. Students who mentioned this theme listed things such as strict rules, no privacy, having to do chores, and being treated like a little child among the reasons that they felt this lack was the worst part of homestays.

I think it will have many limits to living, like sometime you can do something, sometime can't do something, and it will let you feel no no [sic] freedom. (Respondent \#030, NHG) My host family sleep early. I can't go out to night club. (Respondent \#032, HG) I can't keep my private life. If I am child, it's not big problem, but I am 27 years old. SO, I think that is more uncomfortable thing. (Respondent \#061, NHG) Adjusting to the rules of the host home. (Respondent \#114, FHG) Many of these students bring up the fact that college-aged students often think of themselves and are seen by others as adults in their own country, but when they live with a host family in a foreign country they may not be viewed as capable adults. Being viewed and/or treated as a child may stem from the host family's concern for the safety of their student in an unfamiliar culture that could lead to over-protectiveness. In addition, 
even though students may be adults, their lack of command of the foreign language may be such that the host family feels that they must look out for their exchange student more than they would a student from their own country of the same age.

The area of dependence on the host family and being treated like a child of the host family was also investigated with the Likert-scale items. The responses to the items in Category F: Dependence on the Host Family, were mixed. Overall, the students only slightly believed that they should not be very dependent on the host family (mean $=3.37$, $\mathrm{SD}=1.20$ ). Among the individual items, students slightly disagreed with the statement that they should not be expected to do chores $($ mean $=2.70, \mathrm{SD}=1.25)$. They slightly agreed that the host family should treat them like one of the host family's own children (mean $=3.20, \mathrm{SD}=1.13$ ). However, they also slightly agreed that the host family should not give them a curfew (mean $=3.36, \mathrm{SD}=1.20)$ and agreed that they should get a key to the host family's house (mean $=4.03, \mathrm{SD}=.89)$. We have seen that students expect interaction with their host family, that they consider a good host family welcoming and caring, and that they desire the host family to provide a support network; it may be that the students who agree that they should be treated like one of the host family's own children have these aspects of being a child in a family in mind. However, in other areas such as not having a curfew and possibly not having to do chores, students seem to desire not to be given rules like children in the host family may be given.

This theme of being treated as an adult rather than a child seems related to some of the aspects in the theme of convenience in the responses to Item \#3. If a student thinks 
that the best thing about a homestay is that they will not have to do chores or interact on a personal level much with the host family, then the opposite situation of having strict rules imposed upon them by the host family and having little or no private life would make sense as being one of the worst things about a homestay.

Following the theme of lack of being treated as an adult or given freedom, the second most common theme in the responses to Item \#4 was that of the host family and student not getting along due to personality or culture clashes and/or the student's limited proficiency in the foreign language making it difficult to communicate with the host family. In responses that fell into this theme, students mentioned that arguments with members of the host family could also stem from fundamental differences in the life styles of the student and the family and culture shock.

The worst thing is the discommunication. (Respondent \#040, HG) If they didn’t like you. (Respondent \#049, NHG)

If you don't like the family or someone in the family (especially the person the same or of close age to you), it can be unpleasant. (Respondent \#098, FHG) It can be very lonely living with a family that doesn't speak your language. It can be quite the culture shock. (Respondent \#108, HG)

In these areas, the ability to communicate openly with the host family becomes important. Disagreements and miscommunication will most likely occur in every homestay experience, but if they are not addressed they have the potential to become major issues. Students may feel that they would not be able to speak to their host 
families about these issues, however; in responses to the Likert-scale items in Category G: Open Communication, students only slightly believed that they could speak openly with their host family $($ mean $=3.45, \mathrm{SD}=1.08)$.

Closely related to the theme of not getting along with the host family was another of the four most commonly mentioned themes in the responses to Item \#4, that of not being used to the living conditions of the family. In this theme, differences in living conditions from what the student is used to such as the presence of children or pets, the standard of cleanliness in the house, or differences in daily routines were all mentioned as the worst things about homestays.

If there is many small children in the house, I think I can't focus to study.

(Respondent \#005, NHG)

If the home is dirty and they don't have any contact. (Respondant \#018, NHG) This theme also included, however, responses which seemed to neutralize the negative aspects of the homestay:

I'm sure that there are some negatives and difficulties due to change in lifestyle, but I embrace change so for me no matter how bad it might be I would make the most of it. (Respondent \#070, FHG)

I think the first few days are the worst since the host family and the student are both getting the feel of each other and there isn't any set routine yet. After about three days or so though the awkwardness goes away and it all works itself out. (Respondent \#097, HG) 
In these responses we can see that some students, while acknowledging the initial difficulties of living with strangers in an unfamiliar culture, see these difficulties as something that can be overcome and will soften with time. In the same way, it may be possible for students to get used to children or pets in the house. It seems that the difficulties in this category may be easier to overcome than difficulties in the previous theme that stem not from a change in surroundings of daily routine but from a deeper clash of culture or personalities that leads to misunderstandings and arguments.

The fourth major theme in response to Item \#4 is that of getting a bad host family. Students mentioned many criteria by which a host family may be labeled as a bad host family, including the following: the host family is not welcoming, friendly, or helpful; the host family just wants money; the host family ignores the student or does not make the student feel like part of the family; the host family teaches the student bad or wrong things; the host family steals from the student. The following quotes are some examples:

To meet bad host family who only like financial profits or don't give any concerns about my status like improving [the language] or friendship.

(Respondent \#012, NHG)

If they didn't have time to talk with me, and didn't respect me. (Respondent \#019, $\mathrm{HG})$

Thieves, cheat, treat you like animal, wants a lot of money. (Respondent \#046, HG)

If they are not helpful and if they don't talk with you a lot. (Respondent \#059, 
FHG)

Clearly, many students expect that a host family will take the time to talk with them, make them feel welcome, and help them. The risk of living with a host family that only desires to profit from hosting students or goes so far as to steal from their student has been listed as the worst thing about homestays by these students. It is the responsibility of the homestay agency or placement program to find suitable families for their students, but since students have either experienced these issues or are otherwise aware enough of them to list them as the worst thing about homestays, it is obvious that inappropriate families are not always screened out.

Since three of the four themes naming the best things about homestays in response to Item \#3 relate to interpersonal interactions, it is not surprising that one of the themes in response to Item \#4 is this theme of a bad host family ignoring the student. If students believe that a good host family will interact with them on some level, whether it be to teach them culture or language or simply to give them support and a sense of safety in a new environment, families that do not take the time to talk to their students or help them in other ways will necessarily be seen by many students as the worst host families. Among the six smaller themes was the theme of students not knowing enough about their host family in advance:

Students should know this family's living schedule. (Respondent \#004, NHG) It's an unpredictable leap. You might have a good time and learn a lot, or you might not. (Respondent \#079, FHG) 
While having contact with the family in advance may not tell a student for sure whether they will be comfortable, get along, or have a good time and learn from the family, it may at least allow the student to get a sense of the family they will be living with. Furthermore, things like living schedules could definitely be communicated via the agency to the students before they move. It appears that, in addition to screening for good host families, offering students information about the host family may allow homestay agencies to alleviate some of the factors that students believe are the worst things about homestays. Indeed, students agreed fairly strongly that homestay programs should allow them to communicate with their host family before moving on Item \#9 in the Likert-scale section of the questionnaire (mean $=4.13, \mathrm{SD}=.87$ ).

Some students mentioned problems with food as being the worst thing about homestays. Host families may not serve students nutritious food. They probably will not be able to serve food from the student's own culture. In some cases where certain foods cannot be eaten due to religious observances, food can become a major issue for students thinking about homestays.

Some other students' responses formed the theme of always being "on", that is, always having to use the second language, think in terms of the second culture, or be cautious not to offend or intrude upon the host family.

I have to think about how they may feel all the time when I'm going to do anything. (Respondent \#003, HG)

I felt like I was intruding on the family I stayed with. (Respondent \#076, HG) 
The constant immersion could get uncomfortable though dorm life wouldn't be that different. (Respondent \#101, FHG)

Although cultural and language immersion and being in an interactive family environment have been mentioned in previous themes as being helpful aspects of homestays with regards to language learning or even as being the best aspect to homestays, from these responses it is clear that there could also be a tiring and anxietyproducing downside to these aspects that some students are cautious of.

The final three smaller themes were homesickness, distance from the university, and the theme of nothing being bad about homestays. Students who mentioned homesickness pointed out that the host family, although a family, is not your own family. Although previous themes mentioned a support system and new, hopefully lifelong friendships as benefits of a homestay, these students seem to recognize that one may still end up missing one's own family while living abroad. That some students mentioned distance from the university as the worst thing about a homestay contrasts sharply with those responses in the convenience theme of Item \#3 that mentioned proximity to the university as the best thing about homestays. It appears that the distance of the homestay from the school can have quite an effect on polarizing a student's beliefs about the benefits and deficits of a homestay. Finally, some students responded that there was nothing bad about homestays. They may be thinking along the lines as the students mentioned above who, although acknowledging difficulties that may arise, also believe that they can overcome those difficulties, or they may simply believe that homestays are 
purely and completely beneficial for students; there is no way to tell for sure. Table 10 summarizes the results of Item \#4.

Table 10

Item \#4 Results

\begin{tabular}{|l|c|}
\multicolumn{1}{|c|}{\begin{tabular}{c}
\multicolumn{1}{|c|}{ Themes } \\
(Question: What is worst about homestays?)
\end{tabular}} & $\begin{array}{c}\text { Number of Segments in } \\
\text { Theme }\end{array}$ \\
\hline 1. Decreased freedom as an adult & 26 \\
\hline $\begin{array}{l}\text { 2. Host family and student may not get along; } \\
\text { personality/culture clash }\end{array}$ & 25 \\
\hline 3. The student could be placed with a bad host family & 15 \\
\hline 4. Student isn't used to the living conditions & 7 \\
\hline 5. Student may not like the food & 7 \\
\hline 6. Students may not know about the family in advance & 7 \\
\hline 7. There is nothing bad about homestays & 5 \\
\hline 8. The house could be too far from the school & 5 \\
\hline 9. No down-time; student is always "on" & 5 \\
\hline 10. The student may get homesick & $\mathbf{1 2 2}$ \\
\hline Total: & \\
\hline
\end{tabular}

\section{Item \#5}

After asking students about their beliefs about the homestay with regards to language acquisition (Items \#1 and \#2) and what they believe to be the best (Item \#3) and worst (Item \#4) aspects of a homestay, Item \#5 asked students if they had any advice that they would give to someone considering a homestay.

For this item, 32 students either left the item blank or responded that they had no 
advice. Of the students who did respond, I found that five major themes emerged from their responses. Four of the themes occur at roughly the same frequency $(18,21,24$, and 24 segments each), but one of the themes occurs in only four segments.

One of the two themes that occurred most frequently was that of simply giving the advice to do a homestay. These respondents urged the student considering a homestay to try it. Some mentioned the benefits of trying a new experience at least one time.

Go ahead! Just do it. I think it is a experience. (Respondent \#037, FHG) I would like to tell them it's a very good thing if you do. It's helpful in many ways. (Respondent \#048, HG)

It can be a good experience to learn about foreign culture. So try once will be good. (Respondent \#051, HG)

Go for it before you are older and set in your worldviews or your lifestyles. (Respondent \#104, NHG)

Among these recommendations for a homestay was a subset of students that gave a qualified recommendation, that is, they recommended a homestay but only if some condition was met.

If he/she does not have friends or relatives in a foreign country then homestay is the best choice. (Respondent \#006, NHG)

If they are single I think host family is better for them. (Respondent \#015, NHG) In these cases, the advice given to the student takes into consideration factors in the student's life that may weigh into their decision to live with a host family or not. It 
appears that for these students, at least, a homestay is recommended based on the dominant theme in the responses to Item \#3 that the best thing about a homestay is the opportunity for interpersonal interaction that it offers.

The second most frequently occuring theme in response to Item \#5 had to do with the attitude of the student considering a homestay. These responses seemed to assume that the student would choose a homestay and so the respondents gave the student advice on what type of mental or emotional state they should enter into the homestay with. Examples included being respectful, enjoying it, relaxing, being nice, being open-minded and flexible, not being shy, not being judgmental, and not having any preconceived expectations about the experience.

He should not be shy. (Respondent \#036, HG)

Have no expectations about the situation. Understand that personalities are funny things and that anything is possible. (Respondent \#090, FHG)

Be open-minded, respectful, courteous, and try to immerse yourself. (Respondent \#091, FHG)

Just be open to the experience and go with the flow of things. (Respondent \#097, $\mathrm{HG})$

The advice given in this theme addresses how students can mentally prepare themselves for a homestay and try to have a good experience. The responses in the third major theme also assume that the student will choose a homestay and gives advice to make it go smoothly, but this advice is targeted not at the internal mental or emotional processes of 
the student, but at the interactions that the student has with the host family.

Respondents advised a student entering a homestay to follow the host family's rules, to share their own culture, to attempt to refrain from making problems, to help the family, to tell the host family if any problems do arise, and to ask the host family for help if there is anything that the student does not understand.

Don't make problem with them. And be nice. Show what to them is your culture and how you are in your country. (Respondent \#013, NHG) Enjoy staying with homestay as much as you can and try to be friendly to each other, help each other. (Respondent \#066, HG)

Be flexible. Don't feel bad if you can't eat your usual foods or do your usual activities.

Be honest with your host family. If there are serious problems, communicate with the program (Respondent \#098, FHG)

There was a subtheme in the category of working hard to make the homestay a good experience. Students were urged to practice speaking with their host family, to step out of their comfort zones, and to do whatever they could to make the best of the experience.

Get ready to learn everyday from the native family. Try to find the good aspects on them and esteem them, that can help you adjust to the family easy.

(Respondent \#005, NHG)

They should utilize their time by speaking as much as they can with the family. (Respondent \#053, NHG) 
Thus some students recognize that it will take some effort on their part to make the homestay experience go smoothly.

The fourth major theme in response to Item \#5 was that the student should do research before making a decision. This is the only one of the four major categories that actually gives advice to a student who may end up not choosing a homestay (the first category told the student to do a homestay, and the second two categories gave advice on how to make a homestay a good experience, thus assuming that the student has in fact decided to participate in a homestay). In this category, the student was advised to do research on various homestay programs, to ask their advisors or professors for advice, and to search for and choose a good, experienced host family.

Tell to the homestay program all the afraid that he could feel. Also our expectations. (Respondent \#041, HG)

Ask somebody who lived with that family for sure!! (Respondent \#052, HG)

Do the research, talk to people who have had experience and possibly talk with the [host family] beforehand. (Respondent \#092, FHG)

The advice in this category can be split into two groups: advice that may be given to students who are still in their home country considering a homestay, and advice that may be given to students who are already in the foreign country and are looking for a homestay.

In many cases, the student is advised to meet with the family before moving in, but this is not likely to be possible if they are still in their home country when they make 
the choice whether to live in a homestay or not. In situations where a student does not have their own ties to a possible family (in which case they or someone they know already knows the family and can give them information), the homestay program must be the conduit through which the student learns about or exchanges letters, phone calls, or emails with potential host families. Since many respondents advised the student to research good host families and if at all possible contact the family before moving, homestay programs that do not give students and potential host families the means to contact each other before the student actually moves in may not receive as many student clients as those programs that do allow interaction before moving.

In the Likert-scale section of the questionnaire, students only slightly believed that a homestay program would find a good host family for them (mean $=3.49, \mathrm{SD}=.90)$ and they fairly strongly agreed that they should be allowed to communicate with their potential host family before moving (mean $=4.13, \mathrm{SD}=.87$ ). It appears that students believe they will be more likely to find a good homestay if they can speak with the host family before moving, rather than leave everything up to the homestay program.

The final and smallest theme (occurring in only four segments) consisted of respondents advising the student not to do a homestay, but simply to make friends with native speakers and study by themselves.

My advice for student make friend better than take host family. (Respondent \#019, HG)

Just study well. (Respondent \#021, NHG) 
The fact that this theme hardly occurred goes along with the general trend in earlier responses that a homestay will be in some way beneficial for students. Table 11 summarizes the results of Item \#5.

Table 11

Item \#5 Results

\begin{tabular}{|c|c|}
\hline $\begin{array}{c}\text { Themes } \\
\text { (Question: Any advice for a student considering a } \\
\text { homestay?) }\end{array}$ & $\begin{array}{c}\text { Number of Segments in } \\
\text { Theme }\end{array}$ \\
\hline 1. Do a homestay & 24 \\
\hline $\begin{array}{l}\text { 2. Advice pertaining to the attitude of the student; advice } \\
\text { about helpful mental/emotional states to assume }\end{array}$ & 24 \\
\hline $\begin{array}{l}\text { 3. Advice to make interactions with host family go } \\
\text { smoothly }\end{array}$ & 21 \\
\hline $\begin{array}{l}\text { 4. Do research before making a decision (both into } \\
\text { homestay programs in general and the host family in } \\
\text { particular) }\end{array}$ & 18 \\
\hline 5. Don't do a hometsay & 4 \\
\hline 6. (No response/no advice) & $(32)$ \\
\hline Total: & $91(123)$ \\
\hline
\end{tabular}

\section{Item \#6}

Item \#6 differed from the other items in that it asked for the responses only of students who had previously had experience with a homestay. Students were asked if their views on homestays had changed based on their experience. This item investigated whether students perceived their beliefs to have remained static throughout their experience or whether they perceived their beliefs to have changed due to their experience. Students' previous experiences in a homestay could influence what they 
advise other students to do or whether they would choose that type of housing arrangement again in the future, if given the chance. If students' beliefs about homestays change based on their experiences of the homestay, it would be beneficial to discover what about homestays influence or change students' beliefs, and in what direction (favorably or negatively). Knowledge of how a student's experience may influence their beliefs can help us train host families and prepare students so that their opportunities for having an experience with beneficial outcomes increase.

A total of 67 respondents indicated that they had not participated in a homestay before. The responses of the respondents who had homestay experience resulted in 50 coded segments falling into two themes. The first theme, consisting of over half of the coded segments (28) was that their views about homestays had not changed. It is interesting that students perceive their views to have remained static despite the experience of living with strangers in a foreign country with a foreign culture. This cursory question reveals the need for a study that would measure students beliefs before and after a homestay (and perhaps even during with the use of interviews or diaries) and compare the beliefs to see if it really is the fact that so many participants' views do not change. It may be that the students' beliefs do in fact change, but they do not perceive their beliefs to have changed. Of course, this was the last item of a 15-minute survey to which students were asked to respond in 1-3 sentences, so they were not given much time for introspection. Suggestions on how changes in students' beliefs or perceptions of their beliefs may be investigated are given in the Suggestions for Further Research section 
below.

The second theme was that students' views had changed. This category was made up of the two subthemes: the first consisted of the segments where students simply answered "yes" but did not elaborate on how their views had changed.

The second subtheme consisted of the segments where students answered "yes" and elaborated on the changes. The changes were varied and included such things as the students' opinion of a homestay improving, the expectations of the host family changing, their view of people or culture in general changing, or that the homestay was harder than they thought it would be. Two students mentioned that after experiencing a homestay they would not choose to do it again. Table 12 summarizes the results of Item \#6.

Table 12

Item \#6 Results

\begin{tabular}{|l|c|}
\hline $\begin{array}{c}\text { Themes } \\
\text { (Question: If you have experienced a homestay, have } \\
\text { your views about homestays changed based on that } \\
\text { experience?) }\end{array}$ & $\begin{array}{c}\text { Number of Segments in } \\
\text { Theme }\end{array}$ \\
\hline 1. No & 28 \\
\hline 2. Yes & 22 \\
\hline 3. (Not applicable) & $(67)$ \\
\hline Total: & $\mathbf{5 0}(\mathbf{1 1 7})$ \\
\hline
\end{tabular}

\section{Summary of Open-Ended Item Results}

Overall, the open-ended items revealed that students believed homestays to be helpful, especially in the areas of improving language and cultural knowledge. 
Homestays were generally not believed to be necessary for language gain. The best aspects of homestays are the opportunities for interpersonal interaction that they afford students, and the worst aspects included loss of freedoms students were used to as adults, the possibility of clashing with the host family, a change in lifestyle, and the possibility of being assigned to a bad host family. Most respondents advised students considering a homestay to try it and gave tips for preparing themselves mentally and emotionally and for helping the interactions with the host family to go smoothly. Finally, the majority of students who had experienced a homestay did not perceive their beliefs about homestays to have changed based on their experience. 


\section{Results and Discussion: Research Question \#2}

The second research question in this study asked if there were differences in student beliefs about homestays among different groups of students. If the beliefs about homestays are different among groups of students, knowledge of the differences could allow staff in language programs and homestay programs to better work with and counsel students. They may be able to predict questions or difficulties that students might have and be prepared to address those topics for students from varied backgrounds.

For this study, the students were broken into three different groups based on their experience with homestays. Students in the Homestay Group (HG) were students that had participated in a homestay previously or were in a homestay at the time they filled out the questionnaire. Students in the Future Homestay Group (FHG) were students who had not participated in a homestay before but planned to do so. Students in the No Homestay Group (NHG) were students who had not participated in a homestay before and did not plan to do so in the future. The results for the Likert-scale items for each of the student groups are displayed in Table 13. Table 14 displays the mean and standard deviations for the three groups of students in each of the seven categories. Following the tables, I will discuss the findings by category (recall that the survey had seven categories with four items each).

Table 13

Results of Likert-scale items for each group of students

\begin{tabular}{|l|c|c|c|}
\hline Item & Group & Mean & Standard \\
\hline
\end{tabular}




\begin{tabular}{|c|c|c|c|}
\hline & & & Deviation \\
\hline \multirow{3}{*}{$\begin{array}{l}\text { 1. A host family will help me make friends with native } \\
\text { speakers of the language I am studying. }\end{array}$} & HG & 3.67 & 1.15 \\
\hline & FHG & 4.11 & .83 \\
\hline & NHG & 4.06 & .81 \\
\hline \multirow{3}{*}{$\begin{array}{l}\text { 2. Living with a host family is the best way to experience } \\
\text { a new culture. }\end{array}$} & HG & 4.31 & .95 \\
\hline & FHG & 4.34 & .63 \\
\hline & NHG & 3.94 & .93 \\
\hline \multirow{3}{*}{$\begin{array}{l}\text { 3. I will meet more native speakers of the language I am } \\
\text { studying if I live with a host family than if I live in a } \\
\text { dormitory. }\end{array}$} & HG & 3.82 & 1.00 \\
\hline & FHG & 3.79 & .99 \\
\hline & NHG & 3.81 & .98 \\
\hline \multirow{3}{*}{$\begin{array}{l}\text { 4. My host family should not expect me to do chores (for } \\
\text { example: wash dishes, do laundry, watch children, clean } \\
\text { the house). }\end{array}$} & HG & 3.03 & 1.25 \\
\hline & FHG & 2.79 & 1.28 \\
\hline & NHG & 2.29 & 1.13 \\
\hline \multirow{3}{*}{$\begin{array}{l}\text { 5. If more than one student lives with my host family, we } \\
\text { will not be able to learn the language we are studying well. }\end{array}$} & HG & 2.95 & 1.15 \\
\hline & FHG & 3.26 & 1.27 \\
\hline & NHG & 2.52 & 1.07 \\
\hline \multirow{3}{*}{$\begin{array}{l}\text { 6. If I have any problems, the homestay program will help } \\
\text { me. }\end{array}$} & HG & 3.82 & .85 \\
\hline & FHG & 3.79 & .78 \\
\hline & NHG & 3.68 & .83 \\
\hline \multirow{3}{*}{$\begin{array}{l}\text { 7. If there is more than one student living with my host } \\
\text { family we can spend time together. }\end{array}$} & HG & 3.77 & .67 \\
\hline & FHG & 3.92 & .71 \\
\hline & NHG & 3.74 & .82 \\
\hline \multirow{3}{*}{$\begin{array}{l}\text { 8. It is rude to ask my host family to change something for } \\
\text { me. }\end{array}$} & HG & 3.28 & 1.12 \\
\hline & FHG & 2.92 & 1.12 \\
\hline & NHG & 2.68 & .83 \\
\hline \multirow{3}{*}{$\begin{array}{l}\text { 9. The homestay program should let me communicate } \\
\text { with my host family before I leave my country. }\end{array}$} & HG & 4.10 & .75 \\
\hline & FHG & 4.13 & .93 \\
\hline & NHG & 4.26 & .86 \\
\hline \multirow{3}{*}{$\begin{array}{l}\text { 10. I will spend more time with people from my own } \\
\text { country if I live in a dormitory. }\end{array}$} & HG & 3.72 & 1.02 \\
\hline & FHG & 3.74 & 1.03 \\
\hline & NHG & 3.64 & 1.11 \\
\hline \multirow{3}{*}{$\begin{array}{l}\text { 11. A host family will introduce me to their friends and } \\
\text { family. }\end{array}$} & HG & 4.13 & .86 \\
\hline & FHG & 4.03 & .68 \\
\hline & NHG & 3.87 & .72 \\
\hline \multirow{3}{*}{$\begin{array}{l}\text { 12. I can trust a homestay program to find a good host } \\
\text { family for me. }\end{array}$} & HG & 3.38 & 1.09 \\
\hline & FHG & 3.58 & .79 \\
\hline & NHG & 3.45 & .85 \\
\hline \multirow[t]{3}{*}{ 13. If I disagree with my host family, I can tell them. } & HG & 3.69 & 1.03 \\
\hline & FHG & 3.63 & .88 \\
\hline & NHG & 4.10 & .80 \\
\hline \multirow[t]{3}{*}{ 14. Living with a host family will improve my grammar. } & HG & 3.54 & 1.05 \\
\hline & FHG & 4.00 & .96 \\
\hline & NHG & 3.55 & 1.12 \\
\hline \multirow{3}{*}{$\begin{array}{l}\text { 15. Even if I don't like my host family's food, I can't tell } \\
\text { them. }\end{array}$} & HG & 2.51 & 1.17 \\
\hline & FHG & 3.00 & 1.32 \\
\hline & NHG & 2.81 & 1.01 \\
\hline 16. It is best if I am the only & HG & 3.82 & 1.12 \\
\hline
\end{tabular}




\begin{tabular}{|c|c|c|c|}
\hline \multirow[t]{2}{*}{ family. } & FHG & 3.71 & 1.16 \\
\hline & NHG & 3.16 & .78 \\
\hline \multirow{3}{*}{$\begin{array}{l}\text { 17. Every student studying a foreign language abroad } \\
\text { should live with a host family. }\end{array}$} & HG & 3.46 & 1.12 \\
\hline & FHG & 3.24 & .94 \\
\hline & NHG & 2.58 & .89 \\
\hline \multirow{3}{*}{$\begin{array}{l}\text { 18. I will not learn about the host country's culture if I } \\
\text { live in a dormitory. }\end{array}$} & HG & 2.97 & 1.20 \\
\hline & FHG & 2.66 & .99 \\
\hline & NHG & 2.58 & 1.15 \\
\hline \multirow{3}{*}{$\begin{array}{l}\text { 19. A host family will teach me about their country's } \\
\text { culture. }\end{array}$} & HG & 4.10 & .64 \\
\hline & FHG & 4.21 & .66 \\
\hline & NHG & 3.84 & .69 \\
\hline \multirow{3}{*}{$\begin{array}{l}20 . \text { The best homestay program will give me a thorough } \\
\text { orientation about living with a host family. }\end{array}$} & HG & 3.82 & .85 \\
\hline & FHG & 4.05 & .77 \\
\hline & NHG & 4.00 & .86 \\
\hline \multirow{3}{*}{$\begin{array}{l}\text { 21. I will learn more about the country's culture if I live } \\
\text { with a host family. }\end{array}$} & HG & 4.10 & .85 \\
\hline & FHG & 4.29 & .65 \\
\hline & NHG & 3.94 & .77 \\
\hline \multirow{3}{*}{$\begin{array}{l}\text { 22. I will practice the language more living with a host } \\
\text { family than in a dormitory. }\end{array}$} & HG & 4.08 & .98 \\
\hline & FHG & 4.18 & .95 \\
\hline & NHG & 4.00 & .89 \\
\hline \multirow{3}{*}{$\begin{array}{l}\text { 23. Living with a host family will improve my } \\
\text { pronunciation. }\end{array}$} & HG & 4.26 & .72 \\
\hline & FHG & 4.34 & .78 \\
\hline & NHG & 4.23 & .84 \\
\hline \multirow{3}{*}{$\begin{array}{l}\text { 24. My host family should treat me like one of their own } \\
\text { children. }\end{array}$} & HG & 3.23 & 1.09 \\
\hline & FHG & 3.32 & 1.21 \\
\hline & NHG & 2.90 & .79 \\
\hline \multirow[t]{3}{*}{ 25. I cannot tell my host family if I am unhappy. } & HG & 2.56 & 1.05 \\
\hline & FHG & 2.26 & 1.11 \\
\hline & NHG & 2.10 & $\begin{array}{l}.79 \\
\end{array}$ \\
\hline \multirow[t]{3}{*}{ 26. My host family should give me a key to their house. } & HG & 4.36 & .93 \\
\hline & FHG & 3.84 & .82 \\
\hline & NHG & 3.81 & .91 \\
\hline \multirow{3}{*}{$\begin{array}{l}\text { 27. My host family should not tell me what time to come } \\
\text { home each night. }\end{array}$} & HG & 3.54 & 1.29 \\
\hline & FHG & 3.18 & 1.14 \\
\hline & NHG & 3.42 & 1.18 \\
\hline \multirow{3}{*}{$\begin{array}{l}\text { 28. It is okay if there is more than one student living with } \\
\text { my host family as long as we do not speak the same native } \\
\text { language. }\end{array}$} & HG & 3.64 & 1.14 \\
\hline & FHG & 3.29 & 1.21 \\
\hline & NHG & 3.52 & 1.15 \\
\hline
\end{tabular}

Note $. \mathrm{HG}=$ Students who have participated in a homestay before or are currently participating in one; FHG $=$ Students who have not participated in a homestay before but plan to do so; NHG = Students who have not participated in a homestay before and do not plan to do so.

Table 14

Results for categories split by student group 


\begin{tabular}{|l|l|c|c|}
\hline \multicolumn{1}{|c|}{ Category } & Group & Mean & $\begin{array}{c}\text { Standard } \\
\text { Deviation }\end{array}$ \\
\hline \multirow{3}{*}{ A. Homestays and Language Acquisition } & & & 1.03 \\
\hline \multirow{3}{*}{ B. Homestay Program } & HG & 3.83 & 1.00 \\
\cline { 2 - 4 } & FHG & 3.94 & .13 \\
\cline { 2 - 4 } & NHG & 3.59 & .92 \\
\hline \multirow{3}{*}{ C. Culture } & HG & 3.78 & .89 \\
\cline { 2 - 4 } & FHG & 3.89 & 1.06 \\
\cline { 2 - 4 } & NHG & 3.85 & 1.02 \\
\hline \multirow{3}{*}{ D. Interaction with Native Speakers } & HG & 3.87 & 1.06 \\
\cline { 2 - 4 } & FHG & 3.88 & 1.02 \\
\cline { 2 - 4 } & NHG & 3.57 & .90 \\
\hline \multirow{3}{*}{ E. Multiple Boarders } & HG & 3.83 & .92 \\
\cline { 2 - 4 } & FHG & 3.91 & 1.14 \\
\cline { 2 - 4 } & NHG & 3.85 & 1.13 \\
\hline \multirow{3}{*}{ F. Dependence on Host Family } & HG & 3.24 & 1.31 \\
\cline { 2 - 4 } & FHG & 3.25 & 1.09 \\
\cline { 2 - 4 } & NHG & 3.02 & 1.19 \\
\hline \multirow{3}{*}{ G. Open Communication } & HG & 3.51 & 1.01 \\
\cline { 2 - 4 } & FHG & 3.34 & 1.20 \\
\cline { 2 - 4 } & NHG & 3.24 & 3.37 \\
\hline
\end{tabular}

Note $. \mathrm{HG}=$ Students who have participated in a homestay before or are currently participating in one; FHG $=$ Students who have not participated in a homestay before but plan to do so; NHG $=$ Students who have not participated in a homestay before and do not plan to do so.

\section{Category A: Homestays and Language Acquisition}

Students in the Homestay and Future Homestay groups responded similarly to items in this category $(\mathrm{HG}$ mean $=3.83, \mathrm{SD}=1.03 ; \mathrm{FHG}$ mean $=3.94, \mathrm{SD}=1.00)$, indicating that they generally agreed that a homestay would be beneficial for language acquisition. Students in the No Homestay group, while still on the positive side of the scale, did not agree as strongly as students in the first two groups (mean $=3.59, \mathrm{SD}=$ 1.13). It appears that students who do not intend to participate in a homestay do not believe homestays to be as beneficial to language acquisition as students who have participated in a homestay before or who will do so in the future do. Although this is not 
proof of a causal relationship (we cannot assume that some students do not believe a homestay to be as helpful for language acquisition as other students and thus choose not to participate in one) it is reasonable to assume that a student's belief about how beneficial a homestay might be to language acquisition influences their decision of whether to participate in a homestay or not.

Students in all three groups agreed (means at or above 4.00) with items 22 (I will practice the language more living with a host family than in a dormitory) and 23 (living with a host family will improve my pronunciation), indicating that even students who have chosen not to participate in a homestay believe that a homestay can benefit certain aspects of language acquisition. However, while students in the Homestay group and the Future Homestay group slightly agreed with item 17 (Every student studying a foreign language abroad should live with a host family; $\mathrm{HG}$ mean $=3.46, \mathrm{SD}=1.12$; FHG mean $=3.24, \mathrm{SD}=.94)$, students in the No Homestay group slightly disagreed with this statement $($ mean $=2.58, \mathrm{SD}=.89)$. It is interesting to note that the standard deviation for the No Homestay group reaches to the positive side of the scale. Thus some students who may slightly agree that students should live with a host family while studying a foreign language abroad still have indicated that they do not intend to do so. This could mean that they never intend to study abroad, or it could be that other factors override their belief of what might be best for learning a language (such as, for example, financial constraints or concerns about living with strangers).

Finally, it was students in the Homestay group and the No Homestay group who 
responded almost identically $(\mathrm{HG}$ mean $=3.54, \mathrm{SD}=1.05 ; \mathrm{NHG}$ mean $=3.55, \mathrm{SD}=$ 1.12) to item 14 (Living with a host family will improve my grammar), only slightly agreeing with this statement, while students in the Future Homestay group more strongly agreed $($ mean $=4.00, \mathrm{SD}=.96)$. We know from the open-response items that it was the conversational aspects of a homestay that students most believed would benefit his or her language acquisition (pronunciation, speaking and listening practice, learning vocabulary and slang). From the responses to this Likert-scale item, we may speculate that students who intend to participate in a homestay (Future Homestay group) may believe at first that the homestay will also improve their grammatical ability in their second language, but that students who have experienced a homestay (Homestay group) believe (perhaps because of their experiences) that living with a homestay may not improve grammar as much as other aspects of the language. It may be that before entering a homestay students in the Homestay group would have marked this item higher. This would be another are where further research would be of use to ascertain, first, if the grammatical knowledge of students living in a homestay improves compared to students not living in a homestay and, second, if the students' perceptions of their improvement in grammar (or lack thereof) match their actual progress (or lack thereof).

\section{Category B: Homestay Program}

The responses of all three groups of students to the items in Category B were relatively similar $(\mathrm{HG}$ mean $=3.78, \mathrm{SD}=.92 ; \mathrm{FHG}$ mean $=3.89, \mathrm{SD}=.89 ;$ NHG mean $=$ $3.85, \mathrm{SD}=.89)$ 
While students generally agreed with item 6 (If I have any problems, the homestay program will help me; $\mathrm{HG}$ mean $=3.82, \mathrm{SD}=.85 ; \mathrm{FHG}$ mean $=3.79, \mathrm{SD}=$ $.78 ; \mathrm{NHG}$ mean $=3.68, \mathrm{SD}=.83$ ), they only slightly agreed with item 12 (I can trust a homestay program to find a good host family for me; $\mathrm{HG}$ mean $=3.38, \mathrm{SD}=1.09$; FHG mean $=3.58, \mathrm{SD}=.79 ; \mathrm{NHG}$ mean $=3.45, \mathrm{SD}=.85)$. Students in all three groups thus seem to be wary of placing their full trust in the ability of a homestay program to find a good family for them, even if they do believe that the program would help them if they had problems.

Students in all groups agreed more strongly with item 20 (The best homestay program will give me a thorough orientation about living with a host family; HG mean = $3.82, \mathrm{SD}=.85 ; \mathrm{FHG}$ mean $=4.05, \mathrm{SD}=.77 ; \mathrm{NHG}$ mean $=4.00, \mathrm{SD}=.86)$ and item 9 (The homestay program should let me communicate with my host family before I leave my country; $\mathrm{HG}$ mean $=4.10, \mathrm{SD}=.75 ; \mathrm{FHG}$ mean $=4.13, \mathrm{SD}=.93 ; \mathrm{NHG}$ mean $=4.26$, $\mathrm{SD}=.86)$. These results agree with the findings from the open-ended items where students advised others considering a homestay to find a good homestay program and, if at all possible, meet the host family before moving in, or at least contact them if a faceto-face meeting is not possible.

\section{Category C: Culture}

The responses to Category $\mathrm{C}$ were similar to the responses to Category A: Homestays and Language Acquisition, in that the Homestay group and the Future Homestay group agreed slightly more strongly than the No Homestay group that a 
homestay would be beneficial to a student's learning about the host culture (HG mean $=$ 3.87, $\mathrm{SD}=1.06 ; \mathrm{FHG}$ mean $=3.88, \mathrm{SD}=1.02 ; \mathrm{NHG}$ mean $=3.57, \mathrm{SD}=1.06$ ). Students in the Homestay group and the Future Homestay group agreed fairly strongly with item 2 (Living with a host family is the best way to experience a new culture; HG mean $=4.31$, $\mathrm{SD}=.95 ; \mathrm{FHG}$ mean $=4.34, \mathrm{SD}=.63)$, while students in the No Homestay group, although agreeing, agreed less strongly $($ mean $=3.94, \mathrm{SD}=.93)$. A similar pattern can be seen in the responses to item 19 (A host family will teach me about their country's culture; $\mathrm{HG}$ mean $=4.10, \mathrm{SD}=.64 ; \mathrm{FHG}$ mean $=4.21, \mathrm{SD}=.66 ; \mathrm{NHG}$ mean $=3.84, \mathrm{SD}$ $=.69$ ) and item 21 (I will learn more about the country's culture if I live with a host family; $\mathrm{HG}$ mean $=4.10, \mathrm{SD}=.85 ; \mathrm{FHG}$ mean $=4.29, \mathrm{SD}=.65 ; \mathrm{NHG}$ mean $=3.94, \mathrm{SD}$ =.77). Additionally, students in the No Homestay group disagreed more strongly than students in the Homestay group or the Future Homestay group with item 18 (I will not learn about the host country's culture if I live in a dormitory; HG mean $=2.97, \mathrm{SD}=$ 1.20; FHG mean $=2.66, \mathrm{SD}=.99 ; \mathrm{NHG}$ mean $=2.58, \mathrm{SD}=1.15)$.

The responses to the open-ended items indicated that students generally believe a homestay to be beneficial to learning about the host culture, but that students can also learn about the culture even if they do not live with a host family by making friends with native speakers of the language and engaging in activities with them. It may be that students in the No Homestay group do not believe as strongly that a homestay is beneficial for learning about culture because they intend to learn through some of these other channels but, again, more research is necessary to determine how students intend to 
interact with their host culture while abroad before they leave and how they actually do interact while they are abroad.

\section{Category D: Interaction with Native Speakers}

Interestingly, the responses of all three groups of students to Category D were very similar, indicating that all three groups believe a homestay to allow more interaction with native speakers than other living arrangements $(\mathrm{HG}$ mean $=3.83, \mathrm{SD}=1.02 ; \mathrm{FHG}$ mean $=3.91, \mathrm{SD}=.90 ; \mathrm{NHG}$ mean $=3.85, \mathrm{SD}=.92)$. Students in all three groups responded similarly to item 3 (I will meet more native speakers of the language I am studying if I live with a host family than if I live in a dormitory; HG mean $=3.82, \mathrm{SD}=$ 1.00; FHG mean $=3.79, \mathrm{SD}=.99 ; \mathrm{NHG}$ mean $=3.81, \mathrm{SD}=.98)$ and item 11 (A host family will introduce me to their friends and family; $\mathrm{HG}$ mean $=4.13, \mathrm{SD}=.86 ; \mathrm{FHG}$ mean $=4.03, \mathrm{SD}=.68 ; \mathrm{NHG}$ mean $=3.87, \mathrm{SD}=.72)$. However, the responses to item 1 (A host family will help me make friends with native speakers of the language I am studying) showed that while students in the Future Homestay group and the No Homestay group agreed fairly strongly $(\mathrm{FHG}$ mean $=4.11, \mathrm{SD}=.83$; NHG mean $=4.06$, $\mathrm{SD}=.81)$, students in the Homestay group agreed less strongly $($ mean $=3.67, \mathrm{SD}=$ 1.15). This could be another case of the actual experience of living in a homestay affecting the beliefs of the students; while those who have never lived in a homestay may imagine that a host family would help them make friends, those who have experienced a homestay may have come to realize that although a host family will probably allow them to meet more native speakers (item 3, item 11), that, in and of itself, does not guarantee 
that they will make friends with more native speakers (item 1).

All students tended to agree with item 10 (I will spend more time with people from my own country if I live in a dormitory; $\mathrm{HG}$ mean $=3.72, \mathrm{SD}=1.02$; FHG mean $=$ $3.74, \mathrm{SD}=1.03$; NHG mean $=3.64, \mathrm{SD}=1.11)$. The responses to this category have shown that students who do not intend to participate in a homestay share roughly the same beliefs with students who have participated in a homestay and who intend to participate in a homestay regarding the amount of interaction with native speakers a homestay could afford them. Since they seem to be equally aware of the potential benefits as other students but still do not intend to participate in a homestay, it could be that their goals during study abroad are not to interact with native speakers much. Alternatively, it could be that they intend to use some of the strategies that were mentioned in the responses to the open-ended items, such as making friends on campus, going to gyms or coffee shops, or participating in activities or events to interact with native speakers.

\section{Category E: Multiple Boarders}

The responses to Category E were also fairly similar; students in all three groups only very slightly agreed that having multiple boarders in the same homestay is beneficial $(\mathrm{HG}$ mean $=3.24, \mathrm{SD}=1.14 ; \mathrm{FHG}$ mean $=3.25, \mathrm{SD}=1.13 ; \mathrm{NHG}$ mean $=3.02, \mathrm{SD}=$ 1.27). All students generally agreed with item 7 (If there is more than one student living with my host family we can spend time together; $\mathrm{HG}$ mean $=3.77, \mathrm{SD}=.67$; FHG mean $=3.92, \mathrm{SD}=.71 ; \mathrm{NHG}$ mean $=3.74, \mathrm{SD}=.82$ ), but student group responses differed on 
the other three items in this category.

For item 5 (If more than one student lives with my host family, we will not be able to learn the language we are studying well), while students in the Homestay group and the No Homestay group slightly disagreed $(\mathrm{HG}$ mean $=2.95, \mathrm{SD}=1.15 ; \mathrm{NHG}$ mean $=2.52, \mathrm{SD}=1.07)$, students in the Future Homestay group slightly agreed $($ mean $=3.26$, $\mathrm{SD}=1.27$ ). For item 16 (It is best if I am the only student living with my host family), students in the Homestay group and the Future Homestay group agreed $(\mathrm{HG}$ mean $=$ $3.82, \mathrm{SD}=1.12 ; \mathrm{FHG}$ mean $=3.71, \mathrm{SD}=1.16)$ while students in the No Homestay group only very slightly agreed (mean $=3.16, \mathrm{SD}=.78$ ). And finally, for item 28 (It is okay if there is more than one student living with my host family as long as we do not speak the same native language), students in the Homestay group and the No Homestay group agreed more strongly $(\mathrm{HG}$ mean $=3.64, \mathrm{SD}=1.14$; $\mathrm{NHG}$ mean $=3.52, \mathrm{SD}=1.15)$ than students in the Future Homestay group (mean $=3.29, \mathrm{SD}=1.21)$.

Taken together, we can say that students who have participated in a homestay do not necessarily believe that having more than one boarder will hinder their acquisition of the language but are more open to another boarder if they do not share the same native language and, overall, believe that it is best if they are the only student living with their host family. Students who have not participated in a homestay but intend to believe that having another boarder in the same homestay may indeed hinder their language acquisition, are only slightly open to having another boarder in the same homestay even if they speak a different native language, and believe that it would be best if they were the 
only student in their homestay. Students who do not intend to participate in a homestay do not generally believe that having another boarder would hinder their language acquisition, believed that having another boarder who did not share their native language would be fine, and did not strongly believe that it would be best if they were the only boarder in their homestay.

From these responses, we can conclude that the ideal situation for most students would be to be the only boarder with their host family. However, students do seem to be more open to having multiple boarders in their homestay if they all speak a different native language. Students may enjoy the friendship that could come of spending time with another student while at the same time having to rely on the foreign language to communicate, therefore allowing them more practice.

\section{Category F: Dependence on the Host Family}

The responses of students in the Homestay group indicated that they believed more strongly that they should be less dependent on their host family (mean $=3.51, \mathrm{SD}=$ 1.31) than students in the Future Homestay group or the No Homestay group (FHG mean $=3.34, \mathrm{SD}=1.09 ; \mathrm{NHG}$ mean $=3.24, \mathrm{SD}=1.19$ ). Students in the Homestay group neither agreed nor disagreed with item 4 (My host family should not expect me to do chores; mean $=3.03, \mathrm{SD}=1.25$ ), while students in the Future Homestay group slightly disagreed $($ mean $=2.79, \mathrm{SD}=1.28)$ and students in the No Homestay group more strongly disagreed $($ mean $=2.29, \mathrm{SD}=1.13)$. It could be that students who have not chosen a homestay see themselves as more independent in general, and so believe that 
they should engage in chores if they were in a host family. The proximity of the scores of the Homestay group and the Future Homestay group to neither agreeing nor disagreeing may indicate that they believe it may be up to the family to decide this issue and that they have no expectation one way or the other.

Students in the Homestay group and the Future Homestay group slightly agreed with item 24 (My host family should treat me like one of their own children; HG mean = $3.23, \mathrm{SD}=1.09 ; \mathrm{FHG}$ mean $=3.32, \mathrm{SD}=1.21)$ while students in the No Homestay group very slightly disagreed (mean $=2.90, \mathrm{SD}=.79)$. Again, it may be that students in the No Homestay group view themselves as more independent and do not want to be viewed as children, while students who have chosen a homestay may have done so precisely for the family and relational dynamic, which was mentioned as one of the benefits and best things about a homestay in the responses to the open-ended items.

Students in the Homestay group strongly agreed with item 26 (My host family should give me a key to their house; mean $=4.36, \mathrm{SD}=.93$ ) and students in the Future Homestay group and the No Homestay group also agreed, although less strongly (FHG mean $=3.84, \mathrm{SD}=.82 ; \mathrm{NHG}$ mean $=3.81, \mathrm{SD}=.91)$. Although all students seem to agree that they should receive a key, the stronger belief of the Homestay group may come from their actual experience of being in a homestay. A key would give the student more freedom from the host family (they could come and go separately from the family) and lower their dependence on the family (the family would not have to be home when they came home). Interestingly, it was students in the Homestay group and the No Homestay 
group who agreed more strongly with item 27 (My host family should not tell me what time to come home each night; $\mathrm{HG}$ mean $=3.54, \mathrm{SD}=1.29 ; \mathrm{NHG}$ mean $=3.42, \mathrm{SD}=$ 1.18). Students in the Future Homestay group only slightly agreed (mean $=3.18, \mathrm{SD}=$ 1.14). It could be again that the independence of the students in the No Homestay group and the experience of the students in the Homestay group have led to their belief that a curfew is not appropriate, while the students in the Future Homestay group may think themselves more willing to adapt to their host family's rules in the future.

Responses to the open-ended items indicated that this aspect of the homestay is complex; while students depend on their host family for support and companionship and rely on them to teach the culture and language, they at the same time are adults and might not want to feel over-protected or sheltered. They may want to stay out late, go to night clubs, or engage in other activities that they normally would not need to ask anyone's permission to do, but the homestay environment, by its very nature of giving them surrogate parents in the foreign country, may introduce conflict into these situations if the host family does not approve of the actions of their student.

\section{Category G: Open Communication}

Students in the No Homestay group indicated that they believed a student can communicate openly with their host family slightly more strongly than students in the Homestay group and the Future Homestay group $(\mathrm{HG}$ mean $=3.37, \mathrm{SD}=1.09 ; \mathrm{FHG}$ mean $=3.38, \mathrm{SD}=1.01 ; \mathrm{NHG}$ mean $=3.56, \mathrm{SD}=1.20)$. Students in the No Homestay group disagreed with item 8 (It is rude to ask my host family to change something for me; 
mean $=2.68, \mathrm{SD}=.83$ ) while students in the Future Homestay group slightly disagreed $($ mean $=2.92, \mathrm{SD}=1.12)$ and students in the Homestay group slightly agreed $($ mean $=$ $3.28, \mathrm{SD}=1.12$ ). It could be that students in the Homestay group, having experienced a homestay, are more sensitive to the relational dynamics than students in the Future Homestay group and the No Homestay group; it could also be that students in the No Homestay group may see themselves as more independent in general and so are not as hesitant to bring up issues that need to be addressed.

When it comes to food, however, it was students in the Homestay group who disagreed most strongly with item 15 (Even if I don't like my host family's food, I can't tell them; mean $=2.51, \mathrm{SD}=1.17)$, indicating that they believe they can tell their host family if they do not like the food. Since food is such an integral part of daily life, it could be that these students who would generally not ask their host family to change something for them may choose to let smaller things go and address only larger, more important issues. The No Homestay group only slightly disagreed (mean $=2.81, \mathrm{SD}=$ 1.01 ) and the Future Homestay group neither agreed nor disagreed (mean $=3.00, \mathrm{SD}=$ 1.32).

All students disagreed with item 25 (I cannot tell my host family if I am unhappy; $\mathrm{HG}$ mean $=2.56, \mathrm{SD}=1.05 ; \mathrm{FHG}$ mean $=2.26, \mathrm{SD}=1.11 ; \mathrm{NHG}$ mean $=2.10, \mathrm{SD}=.79$ ) and agreed with item 13 (If I disagree with my host family, I can tell them; HG mean = $3.69, \mathrm{SD}=1.03 ; \mathrm{FHG}$ mean $=3.63, \mathrm{SD}=.88 ; \mathrm{NHG}$ mean $=4.10, \mathrm{SD}=.80)$. As with item 8, it was the No Homestay group that held the strongest beliefs in these areas. 
However, since students in the Homestay group and the Future Homestay group also generally believed that they could tell their host family if they disagreed or if they were unhappy, it can again be assumed that students do feel that they can talk about important issues, even if they also believe it may be rude to do so.

The responses to this category are related to the responses to the open-ended items where students indicated that one of the worst problems with a homestay would be getting a family that the student does not get along with or that is not welcoming to the student. Since the student is coming from another country and living with strangers, there is a lot of pressure that can build up in an attempt not to be rude or appear ungrateful. At the same time, students are adjusting to a new culture and lifestyle and there may be issues that need to be discussed. Thus, the ability and willingness to communicate openly can have a large effect on the atmosphere and relative success of a homestay experience. 


\section{Conclusions}

As discussed above, there is little research on the beliefs language learners hold about homestays. The results of this study help us to better understand the students' perspective by illuminating several areas in which students hold beliefs about homestays. The students in this study in general believe a homestay to be beneficial to language and culture acquisition. These findings are consistent with research that has been done with students studying abroad (Freed, 1998; Ife, 2000; Schmidt-Rinehart, 2010). However, most students do not believe a homestay to be necessary to language acquisition. Since a homestay is not believed to be necessary for language acquisition, what are other possible reasons students might have for choosing a homestay while studying abroad?

Students believe that living with a homestay can provide an inside look into the cultural and family life of a country in a way that no other living situation can. Students also believe that a homestay can provide more opportunities for interaction with native speakers, a support network for students living in a new country, and practice especially in conversation, vocabulary, and pronunciation in the target language. They also see homestays as beneficial in providing the opportunity to create lasting friendships and take part in activities they may not have access to living on their own.

Prior researchers have noted that students believe staying with a host family will give them frequent, if not daily, access to interaction with native speakers of the language they are studying (Fryer \& Lukasevich, 1998; Gutel, 2007; Kaplan, 1989; Wilkinson, 2002; Yager, 1998), consistent with the findings of this study. However, although 
students may believe a homestay will grant them automatic access to native speakers, this may not always be the case. Host families may consist of a single working adult who is absent from the house or tired most of the time, for example. In other cases, interaction may not proceed as smoothly as students might envision, due to personality or cultural differences or the student's lack of proficiency in the foreign language. Researchers, although acknowledging that students believe they will interact often with host families, have found that many students who have experienced homestays did not in fact interact with their hosts as much as they had anticipated they would (Magnan \& Back, 2007; Rivers, 1998; Tanaka, 2007; Wilkinson, 1998a; Wilkinson, 2002; Woodall \& Takeuchi, 1999).

Although the students in this study believe that homestays will aid them in linguistic and cultural immersion and can provide benefits such as a safe home, new friendships, and a support network while abroad, they also believed that there are some drawbacks to living with a host family. Students are concerned about the amount of freedom they, as adults, receive (or do not receive) from their host parents. Clashes of culture or personality can lead to very awkward living conditions. A student's lack of proficiency in the foreign language may lead to miscommunication or a lack of communication over important issues. Families and students may also disagree when it comes to expectations of the role of the student in the household with regards to things like chores and curfews.

Disagreements, misunderstandings, a lack of clarity about the roles of the students 
and the host family members, and general disappointment in homestays may stem from a lack of thorough preparation for both parties before the homestay begins. Many researchers have found that these types of negative incidents regularly occur during homestays, and have recommended that homestay providers work to reduce these incidents by providing students and host families with thorough orientations and information about each other prior to the actual homestay (Campbell, 2004; Crealock, et al., 1999; Fryer \& Lukasevich, 1998; Kendall-Smith \& Rich, 2003; Rivers, 1998; Schmidt-Rinehart \& Knight, 2004).

Due to the lack of previous research, it was necessary to create an original instrument for this study to investigate learner beliefs regarding homestays. Both quantitative and qualitative data were gathered, which provided insights from slightly different approaches and allowed for the triangulation of the data. Both types of data were gathered at the same time, analyzed, and compared to offer a deeper view into the beliefs than either alone may have done (Ivankova \& Creswell, 2009). Although the items in the Likert-scale section of the questionnaire were developed using data gathered from personal experience, interviews with faculty and staff in the PSU Applied Linguistics Department and IELP, casual conversations with language students, and a survey of previous research, they were still constructed items that did not allow for flexibility in the students' responses. Students simply indicated how much they agreed or disagreed with the statements on a 5-point scale, and one student's "slightly agree" may not be of exactly the same magnitude of another student's. However, the quantitative 
data gave an overall picture of the general beliefs of students regarding the seven categories that were investigated and were useful in conjunction with the qualitative data to expand on or confirm themes that arose.

The qualitative data were useful to give a picture of what students believe about homestays from their own thoughts, with flexibility in answering. That students' openended responses could be grouped into general themes shows that students do indeed have beliefs about homestays and that students share many beliefs. When a theme that arose had also been included in the quantitative portion of the questionnaire, the data could be triangulated to investigate that theme from more than one approach. For example, in the open-ended responses, themes arose showing that students believed homestays to be of great help in language and culture acquisition while studying abroad; these findings were confirmed in the quantitative data with the results of Category A: Homestays and Language Acquisition $($ mean $=3.79)$ and Category C: Culture $($ mean = 3.77). Students, in the open-ended responses, described many roles that the homestay program should play in the homestay process, and the belief that the homestay program should be heavily involved in making the homestay go smoothly was confirmed with the results of Category B: Homestay Program (mean $=3.83$ ). Likewise, Categories D: Interaction with Native Speakers, F: Dependence on Host Family, and G: Open Communication, all were mirrored in themes that arose in the open-ended responses and the two types of data were consistent with each other.

The only category in the quantitative section of the questionnaire that did not arise 
as a theme in the open-ended responses was Category E: Multiple Boarders. It could be that the majority of students do not consider this possibility when they think of homestays; although the issue of multiple boarders came up (usually in a negative light) in all of the sources for the Likert-scale item construction, the problems of multiple boarders may have come up frequently simply because this situation often brings about complaints. A small number of occurrences may be resulting in a large number of complaints. However, more research is needed to determine the relative importance of the issue of multiple boarders to students in general.

When students were split into groups and compared for the second research question of this study, although no differences were found in the polarization of the means of the groups for the seven overall categories (there was no case where the mean of one or two groups was on the negative side of the scale and the mean of the other group(s) was on the positive side) there were differences in magnitude between some groups in some categories-most notably in Categories A: Homestays and Language Acquisition, C: Culture, and E: Multiple Boarders, where the Homestay and Future Homestay groups agreed more strongly than the No Homestay group. The scores of the Homestay Group and the Future Homestay group were fairly similar (within .11 of each other and in three cases within .01 of each other) with the exception of Category F: Dependence on Host Family, where they differed by .17. Responses to individual items within each of the categories varied; in some cases all three groups were similar, in some cases two groups were similar while a third was distant, and in some cases all three 
groups were distant from each other.

Statistical significance of the differences (or lack thereof) between groups could not be determined. The data for the seven categories were prepared for a MANOVA to investigate differences in the mean responses of the seven categories among the three student groups, but the data violated the homogeneity of variance-covariance matrices for the test (Box's M was significant at $\mathrm{p}=.022$ ), indicating that the results from the MANOVA could not be considered valid (Field, 2009). Although the statistical significance of the differences could not be determined, the results are still useful to show the general trends of beliefs among these three groups of students and serve to shed light on areas that can be investigated in future research.

It is important to note that the findings of this study, although presented in terms of student groups or themes occurring in the responses to the open-ended items, are in reality an aggregation of the individual voices and beliefs of 116 different students. In order to gain an understanding of commonly occurring beliefs it is most useful to group students or their responses according to specific criteria (such as, in this study, experience with homestays or intent to participate in a homestay) or themes that arise in the data. These themes can then serve as general categories of student beliefs and can be used to create training materials for staff interacting with students or orientation materials for the students themselves.

However, it must also be remembered that, especially in the qualitative section of the questionnaire, the responses of the students all come from individuals who each have 
their own unique experiences or opinions with regards to homestays. As Hood (2009) notes, "Different people will experience the same event differently, constructing different explanations, drawing different conclusions, learning different lessons and, importantly, telling different stories about it" (p. 81). Thus it is important not to forget that the data in this study come from students who each have their own insights into homestays in order to avoid the danger of over-generalizing the application of the results of this study to all students in every context.

At the same time, the major strength of this study is precisely the fact that the data is drawn directly from students and, in the qualitative section, in their own words. Even the formation of the questionnaire (especially the Likert-scale section) took into account student voices as sources for the seven categories and 28 individual items used to investigate student beliefs about homestays. In addition, my own personal experience of having studied abroad twice, living in a homestay the first time and in a student dormitory the second time, was drawn upon in the formation of the items. In other words, the questionnaire was not only created based on input from publications and professionals in the field of applied linguistics, but was also based on the lived experiences of language students themselves. Since this study represents the beliefs of students about homstays in their own words (qualitative section) or in response to items based in part on their own words (quantitative section), we can be confident that the findings of this study are relevant to students and can be used as a reference to help improve many aspects of the homestay experience. 


\section{Practical Implications}

The results of this study can be useful to staff of both language institutions and homestay providers and, indirectly via those staff, to students currently participating in a homestay or considering a homestay in the future. Staff in language institutions working with students staying with host families can keep these issues in mind when talking with students. If students come to staff with concerns over their host family it can be useful for staff to recognize the conflicts that may arise. Staff may wish to ask students why they chose a homestay first to better understand whether they were putting more value on one of the categories of language acquisition, cultural acquisition, support network and family dynamics, or some mixture of those and other areas. Knowing the general reasons a student has chosen a homestay may help staff to troubleshoot disappointments or conflicts that have arisen in various situations.

Staff can also advise students on good communication strategies and conflict resolution. If students have a problem with their host family but have not yet brought it up, it may be because they believe it would be rude to do so, but it may also be because they simply lack the proficiency and confidence to believe they can handle that type of potentially confrontational conversation. Another possible reason is that the student has personal or cultural difficulty relating to a member or members of their host family. Once staff have ascertained which of these factors is playing into the student's reluctance to speak with their host family (and it may be a mixture of 2 or more) they can better address strategies to assist the student with specific problem areas. For example, in the 
first situation, they may focus on helping the student to see that raising areas of concern is not rude but could be very helpful in resolving issues smoothly. In the second situation, they could focus on giving the student vocabulary and pragmatic strategies for this type of difficult interaction, and practicing with the student to raise the student's confidence. In the third situation, staff may be able to help students become aware of cultural differences or personality differences that may be causing problems and give advice on how to address and overcome them. Having the background knowledge of what are common issues that students have in homestays can in these ways help staff prepare to better address these problems with their students.

Homestay programs can also benefit from this study. Results from both the Likert-scale items and open-ended items show that students generally desire to contact their potential host families before moving in. Even if face-to-face meetings are not possible, homestay programs that set up email, telephone, skype, letter, or other bridges of communication between students and families prior to students leaving their home countries are likely to be able to spot potential problems before the student has actually moved. Both the student and the family can better prepare for the move the more information they have about the other party. When students choose homestay programs to work with, they may be more likely to choose programs that provide this type of service. Furthermore, if students are not very proficient yet in the target language, homestay programs could assist students in contacting host families by offering translation of letters or emails sent between the host family and the students. 
It also became apparent that students are not entirely confident in homestay programs' ability to choose good host families. Students worry about being placed with a family that is only interested in the monetary benefits of hosting a foreign student, or being placed with a family that is not welcoming and does not have time to spend with the student. Homestay programs that work to eliminate these types of families from their rosters may be able to build better reputations and attract more students to their business. Many homestay placement programs advertise that they interview potential host families and carefully choose the families that they employ to host students. It may help to boost students' confidence in this process if homestay programs made their standards for the host families they choose available to the students. What requirements must a family meet in order to be allowed to host? What topics are covered in the interview? Making this information known to students may give students a better idea of what type of families each placement program may employ.

However, since whatever screening processes placement programs use can and do miss some indicators of unsuitability to be a host family (students do sometimes get placed with families who are not welcoming, who may not interact with them, who may only want rent money, etc.) it may also be beneficial for every student to complete a posthomestay evaluation of their host family for the placement program to keep on record. Students could use this evaluation to communicate to the placement program potential areas in which that particular host family may not be meeting the standards they advertise to their students. At the same time, if student evaluations of host families are collected, 
the host family should also turn in an evaluation of the experience from their perspective. This may help the placement program to spot areas where the issue under question is not the family's suitability to host students but rather some breakdown in communication, misunderstanding, or disagreement between the student and the family.

In addition, as was mentioned in the discussion of the open-ended items, it may benefit homestay programs and students to explicitly state the many different forms a host family may take. In particular, host families in the United States range from singles (of all ages, with or without children) to couples (married or not, of all ages, with or without children, heterosexual or homosexual) and may in some cases include immigrants to the United States whose native language may not be English. All of these families can doubtless provide welcoming environments for students, but who may be expecting a certain type of family could benefit from being prepared in advance for the variety of different host families they may be placed with. Alternatively, if a homestay placement program screens families who fall into certain categories out, they should inform students of their screening criteria so that, again, students can know what to expect when they apply for a host family. This type of transparency may improve students' confidence in homestay placement programs.

Students indicated that they expect support from their homestay program in the event of a problem, and most students indicated that a good homestay program would provide them with an orientation to living with a host family. An orientation could include information about reasonable expectations of a host family, common cultural 
misunderstandings that may arrive, communication strategies, and other factors that have the potential to cause conflict in a homestay. Giving students information about these issues beforehand may help to prevent major conflicts from happening. The results from this study can be used as a general outline of topics that would be beneficial to include in orientation materials. Specifically, the themes that arose in the responses to open-ended items \#1-5 could be addressed.

A homestay program's policy on placing multiple boarders with families may also influence the experience that students have while living with a host family. Although the issue of multiple boarders did not come up in the open-ended item responses, from the Likert-scale items we were able to see that most students would prefer that they were the only student with their host family. If they do have another boarder in the same homestay, students generally preferred that the other boarder speak a different native language. It should be acknowledged that homestay placement programs may also be working under logistical restraints. They may have more student applicants than host families. Under these circumstances, the advantages of being able to place students with host families should be weighed against the strength of the individual students' desires regarding multiple boarders. Perhaps homestay programs can include an item in their application forms where the student can indicate whether they are willing to be placed in a host family with multiple boarders.

Overall, the results of this study have shown that students do share general beliefs about homestays. Students who have experienced a homestay or intend to participate in a 
homestay may have different beliefs than students who do not intend to participate in a homestay on some issues. Although holding different beliefs does not necessarily indicate that differences in beliefs caused students to choose or decline to participate in a homestay, it does appear that their beliefs and their decisions about housing options may be related. As has been shown in prior research, students' beliefs can influence choices they make with regards to their language education (Fernandez, 2008; Laubscher, 1994). Further research is needed to discover which beliefs are held most strongly by students and whether students' beliefs change after experiencing a homestay. 


\section{Limitations of the Study}

There were limitations to this study that were encountered as the study progressed or became apparent while analyzing the data gathered by the questionnaire. One of the limitations was a lack of representation of students studying certain foreign languages. The choice of whether to allow the questionnaire to be administered in a class was up to the instructor of the class; thus, the students responding to the questionnaire were mostly studying English, French, or Russian. No Spanish, Japanese, Chinese, or Arabic classes (programs with many students at PSU) were represented in this study. This may have led to some beliefs about homestays that have to do with the student's impression of the culture of the host country not appearing in the responses to the questionnaire.

Another limitation was a somewhat low response rate in some of the classes. Since the questionnaire was given to students to do at home and return in many classes, the response rate was lower than what might have been achieved had all of the questionnaires been administered in class and the students who did the questionnaire on their own time and returned it to their teacher may fall into a different demographic than students who did not.

The questionnaire should be revised before it is used again. The instrument should undergo a process of validation whereby it can be ascertained which items actually do correlate into categories and which items need to be modified or replaced. The data gathered in this study could be used to discover whether there are any existing items that do not belong in certain categories, and further item construction and pilot 
testing could be used to develop the most appropriate items for each category. Since there was a violation in the assumption of the homogeneity of the variance-covariance matrices for the MANOVA, one or more of the seven categories in the questionnaire may correlate strongly with another category. These categories may in fact be measuring the same variable. The data gathered from this study can be analyzed to determine which categories correlate and those categories can be combined in future revisions of the instrument so that accurate statistical analyses may be done.

Furthermore, there are a number of smaller modifications that should be done. There should be reverse-coded items in each category instead of only in three. Items should be piloted with several variations of the questionnaire that have only slight wording differences so that the most unambiguous items may be chosen. The data from the open-ended section of this questionnaire may be used to create more relevant items to investigate in the Likert-scale section, targeting the themes that occurred most frequently. For example, one of the categories in the Likert-scale section, that of multiple boarders, did not come up in the responses to the open-ended questions. The questionnaire should be modified to reflect issues such as this one that become apparent through piloting and use. Finally, in future administrations of the questionnaire, a script should be included so that all participants can hear the exact same introduction to the research and instructions for filling out the questionnaire. 


\section{Suggestions for Further Research}

The results of this questionnaire suggest many possible roads for further research. In the first place, as was described briefly in the discussion of the results to the openended item \#6, a study could be done to discover whether the beliefs that students have about homestays change over the course of their homestay experience. Students' perceptions of their beliefs would also be investigated; it may be that beliefs change but students are not aware of the changes. For a study such as this, students may be given a questionnaire like the Student Beliefs about Homestays Questionnaire used in this study before and after their homestay experience. The responses to the pre- and postquestionnaires could then be compared to discover if there are any differences. Students may also be interviewed before, during, and after a homestay. In addition, students may be asked to keep a journal of their experience and reflections on the experience as they stay with their host family, which could be analyzed after the homestay was completed to investigate how beliefs or perceptions of beliefs may change over time.

One study that would likely be of great use to homestay programs especially in America would investigate what students picture as the ideal host family. This investigation could include family make-up and lifestyle in addition to discovering what roles the student expects the members of the host family to play for them (explicit teacher of language, cultural guide, friendly person to speak to daily, support net, chef/servant, etc.). This information could be used by homestay programs to help give students a more accurate view of what they can expect from a host family and to better select and train 
host families that would meet the needs of the students.

Another study that could be of use to homestay programs would investigate what services students expect an ideal homestay program to provide. As became apparent in this study, most students desire to have some contact with their host family before moving, and yet some homestay programs may not offer this opportunity. There may be other areas in which students desire certain services from their homestay programs.

One study that could greatly benefit students would involve collecting the advice of students who are finishing homestays and making it available to students who are beginning a homestay or considering a homestay. The responses to open-ended Item \#5, asking for advice, were varied and seemed to represent a mixture of practical and emotional advice ranging from the process of finding a host family, to preparing for moving, to what to do after one has moved. A study designed to more carefully investigate the advice (and possibly anecdotes) of students who have completed a homestay could be used to create a website, booklet, or other type of material that could be made accessible to students in programs like the IELP who are considering or just beginning a homestay.

Finally, this study compared students based on only one factor, that of whether they had experienced a homestay or not and, if they had not, whether they intended to. Studies in the future could investigate students based on different factors such as gender, age, or native language or culture. All of these possible groupings are likely to reveal aspects of students' beliefs about homestays that can be used to improve the homestay 
experience for all involved: the students, the host families, the homestay programs, and the staff at the schools the students are attending. 


\section{References}

Brown, D. B. (2009). Open-response items in questionnaires. In J. Heigham \& R. A. Croker, (Eds.), Qualitative research in applied linguistics: A practical introduction (pp. 200-219). England: Palgrave Macmillan.

Campbell, N. (2004). Home(stay) is where the heart(ache) is: A study of Chinese international students living with local families in New Zealand. Australian Journal of Communication, 31, 107-134.

Churchill, E. (2003). Competing for the floor in the American home - Japanese students sharing host families -. Kanagawa University Studies in Language, 25, 185-202.

Cotterall, S. (1999). Key variables in language learning: what do learners believe about them? System, 27, 493-513.

Cowie, N. (2009). Observation. In J. Heigham \& R. A. Crocker, (Eds.), Qualitative research in applied linguistics: A practical introduction (pp. 165-181). England: Palgrave Macmillan.

Crealock, E., Derwing, T. M., \& Gibson, M. (1999). To homestay or to stay home: The Canadian-Japanese experience. TESL Canada Journal/Revue TESL du Canada, $16(2), 53-61$.

Creswell, J. W. (2006). Qualitative inquiry and research design: Choosing among five approaches. Thousand Oaks, CA: Sage Publications, Inc.

$\mathrm{D} \square \mathrm{rnyei}, \mathrm{Z}$. (2003). Questionnaires in second language research: Construction, administration, and processing. Mahwah, NJ: Lawrence Erlbaum Associates, Inc. 
$\mathrm{D} \square \mathrm{rnyei}, \mathrm{Z}$. (2007). Research methods in applied linguistics. Oxford, England: Oxford University Press.

Fernandez, C. (2008). Persistence in foreign language study: an investigation of learners' beliefs. In Siskin, J. S. (Ed.), AAUSC 2007: From thought to action: exploring beliefs and outcomes in the foreign language program (pp. 135-152). Boston, MA: Thomson Heinle.

Field, A. (2009). Discovering statistics using SPSS $3^{\text {rd }}$ ed. London, UK: Sage Publications.

Freed, B. F. (1998). An overview of issues and research in language learning in a study abroad setting. Frontiers: The Interdisciplinary Journal of Study Abroad, 4(2), $31-60$.

Fryer, C., Lukasevich, A. (1998). Home away from home: Eight female Japanese students share their North American homestay experiences. American Language Review, 2(4), 14-17.

Gutel, H. (2007). The home stay: A gendered perspective. Frontiers: The Interdisciplinary Journal of Study Abroad, 15, 173-188.

Hansel, B. (2007). The exchange student survival kit $2^{\text {nd }}$ ed. Boston, MA: Intercultural Press.

Hood, M. (2009). Case study. In J. Heigham \& R. A. Crocker, (Eds.), Qualitative research in applied linguistics: A practical introduction (pp. 165-181). England: Palgrave Macmillan. 
Horwitz, E. (1988). The beliefs about language learning of beginning university foreign language students. The Modern Language Journal, 72(3), 283-294.

Hosenfeld, C. (2003). Evidence of emergent beliefs of a second language learner: A diary study. In Kalaja, P., Barcelos, A. M. F. (Eds.), Beliefs About SLA: New Research Approaches (pp. 3754). Dordrecht, The Netherlands: Kluwer Academic Publications.

Ife, A. (2000). Language learning and residence abroad: How self-directed are students? Language Learning Journal: Journal of the Association for Language Learning, $22,30-37$.

Iino, M. (2006). Norms of interaction in a Japanese homestay setting: toward a two-way flow of linguistic and cultural resources. In DuFon, M. A., Churchill, E. (Eds.), Language learners in study abroad contexts (pp. 151-176). Clevedon, UK: Multilingual Matters Ltd.

Ivankova, N. V., Creswell, J. W. (2009). Mixed methods. In J. Heigham \& R. A. Crocker, (Eds.), Qualitative research in applied linguistics: A practical introduction (pp. 165-181). England: Palgrave Macmillan.

Kaplan, M. A. (1989). French in the community: A survey of language use abroad. The French Review, 63(2), 290-301.

Kendall-Smith, M., Rich, P. (2003). Satisfactions and dissatisfactions of homestay hosts with sojourn students. New Zealand Journal of Educational Studies, 38(2), $165-$ 177. 
Knight, S. M., Schmidt-Rinehart, B. C. (2010). Exploring conditions to enhance student/host family interaction abroad. Foreign Language Annals, 43(1), 64-79.

Laubscher, M. R. (1994). Encounters with difference: Student perceptions of the role of out-of-class experiences in education abroad. Westport, CT: Greenwood Press.

Liao, P. (2006). EFL learners' beliefs about and strategy use of translation in English learning. Regional Language Centre Journal, 37(2), 191-215.

Magnan, S. S., Back, M. (2007). Social interaction and linguistic gain during study abroad. Foreign Language Annals, 40(1), 43-61.

Mori, K. (1999). Beliefs about language learning and their relationship to the ability to integrate information from word parts and context in interpreting novel kanji words. The Modern Language Journal, 83(4), 534-547.

Peacock, M. (1999). Beliefs about language learning and their relationship to proficiency. International Journal of Applied Linguistics, 9(2), 247-265.

Rifkin, B. (2000). Revisiting beliefs about foreign language learning. Foreign Language Annals, 33(4), 394-408.

Rivers, W. P. (1998). Is being there enough? The effects of homestay placements on language gain during study abroad. Foreign Language Annals, 31(4), 492-500.

Sakui, K., Gaies, S. J. (1999). Investigating Japanese learners' beliefs about language learning. System, 27, 473-492.

Schmidt-Rinehart, B. C., Knight, S. M. (2004). The homestay component of study abroad: Three perspectives. Foreign Language Annals, 37(2), 254-262. 
Tanaka, K. (2007). Japanese students' contact with English outside the classroom during study abroad. New Zealand Studies in Applied Linguistics, 13(1), 36-54.

Vande Berg, M. (2007). Intervening in the learning of U.S. students abroad. Journal of Studies in International Education, 11, 392-399.

Victori, M. (1999). An analysis of writing knowledge in EFL composing: A case study of two effective and two less effective writers. System, 27, 537-555.

Wilkinson, S. (1998a). On the nature of immersion during study abroad: Some participant perspectives. Frontiers: The Interdisciplinary Journal of Study Abroad, 4(2), 21 38.

Wilkinson, S. (1998b). Study abroad from the participants' perspective: A challenge to common beliefs. Foreign Language Annals, 31(1), 23-39.

Wilkinson, S. (2002). The omnipresent classroom during summer study abroad: American students in conversation with their French hosts. The Modern Language Journal, 86, 157-173.

Woodall, B., Takeuchi, Y. (1999). Language experience in the homestay environment. Journal of Intensive English Studies, 13, 35-52.

Yager, K. (1998). Learning Spanish in Mexico: The effect of informal contact and student attitudes on language gain. Hispania, 81(4), 898-913.

Yang, N. (1999). The relationship between EFL learners' beliefs and learning strategy use. System, 27, 515-535. 


\section{Appendix: Student Beliefs About Homestays Questionnaire}

The purpose of this questionnaire is to discover beliefs that students who study a foreign language have about homestays. This questionnaire is anonymous. The results of this questionnaire will be used to help students and homestay programs in the future. If you have any questions about this questionnaire or the results of this study, you can email Sara Juveland (juveland@pdx.edu). This questionnaire should take around 15 minutes. Thank you for your time and assistance!

\section{Part 1: Demographics (Used to compare groups)}

Instructions: Please answer the following questions. This information will be used to classify and compare the data from the questionnaire. It will not be used for any other purpose. You cannot be identified from this information.

1. Have you ever studied abroad (in a country other than your home country) or are you studying abroad now?
a. Circle one: Yes No

2. If you have studied abroad, did you live with a host family?
a. Circle one: Yes No

b. If "yes", for how long?

3. If you were to study abroad in the future, would you plan to live with a host family?
a. Circle one:
Yes
No

4. What is your native language?

5. What language are you currently studying?

a. How long have you studied this language?

6. If you have studied any other languages, please list them below.

a.

b.

c.

7. What is your gender?
a. Circle one:
Male
Female

8. What is your age? 
9. Has your family ever hosted an exchange student before?
a. Circle one: Yes No
b. If "yes", for how long?

\section{Part 2: Beliefs}

Instructions: Read each statement below. For each statement, circle only one number on the scale (from 1-5) to show whether you agree or disagree.

\begin{tabular}{|c|c|c|c|c|c|}
\hline \multicolumn{2}{|l|}{$1=$ Strongly Disagree $2=$ Disagree $3=$ Neither Disagree or Agree } & $4=$ Agree & \multicolumn{3}{|c|}{$5=$ Strongly Agree } \\
\hline $\begin{array}{l}\text { 1. A host family will help me make friends with native } \\
\text { speakers of the language I am studying. }\end{array}$ & 1 & 2 & 3 & 4 & 5 \\
\hline $\begin{array}{l}\text { 2. Living with a host family is the best way to experience a } \\
\text { new culture. }\end{array}$ & 1 & 2 & 3 & 4 & 5 \\
\hline $\begin{array}{l}\text { 3. I will meet more native speakers of the language I am } \\
\text { studying if I live with a host family than if I live in a } \\
\text { dormitory. }\end{array}$ & 1 & 2 & 3 & 4 & 5 \\
\hline $\begin{array}{l}\text { 4. My host family should not expect me to do chores (for } \\
\text { example: wash dishes, do laundry, watch children, clean the } \\
\text { house). }\end{array}$ & 1 & 2 & 3 & 4 & 5 \\
\hline $\begin{array}{l}\text { 5. If more than one student lives with my host family, we } \\
\text { will not be able to learn the language we are studying well. }\end{array}$ & 1 & 2 & 3 & 4 & 5 \\
\hline $\begin{array}{l}\text { 6. If I have any problems, the homestay program will help } \\
\text { me. }\end{array}$ & 1 & 2 & 3 & 4 & 5 \\
\hline $\begin{array}{l}\text { 7. If there is more than one student living with my host } \\
\text { family we can spend time together. }\end{array}$ & 1 & 2 & 3 & 4 & 5 \\
\hline $\begin{array}{l}\text { 8. It is rude to ask my host family to change something for } \\
\text { me. }\end{array}$ & 1 & 2 & 3 & 4 & 5 \\
\hline $\begin{array}{l}\text { 9. The homestay program should let me communicate with } \\
\text { my host family before I leave my country. }\end{array}$ & 1 & 2 & 3 & 4 & 5 \\
\hline $\begin{array}{l}\text { 10. I will spend more time with people from my own country } \\
\text { if I live in a dormitory. }\end{array}$ & 1 & 2 & 3 & 4 & 5 \\
\hline
\end{tabular}




\begin{tabular}{|c|c|c|c|c|c|}
\hline $\begin{array}{l}\text { 11. A host family will introduce me to their friends and } \\
\text { family. }\end{array}$ & 1 & 2 & 3 & 4 & 5 \\
\hline $\begin{array}{l}\text { 12. I can trust a homestay program to find a good host family } \\
\text { for me. }\end{array}$ & 1 & 2 & 3 & 4 & 5 \\
\hline 13. If I disagree with my host family, I can tell them. & 1 & 2 & 3 & 4 & 5 \\
\hline 14. Living with a host family will improve my grammar. & 1 & 2 & 3 & 4 & 5 \\
\hline $\begin{array}{l}\text { 15. Even if I don't like my host family's food, I cannot tell } \\
\text { them. }\end{array}$ & 1 & 2 & 3 & 4 & 5 \\
\hline $\begin{array}{l}\text { 16. It is best if I am the only student living with my host } \\
\text { family. }\end{array}$ & 1 & 2 & 3 & 4 & 5 \\
\hline $\begin{array}{l}\text { 17. Every student studying a foreign language abroad should } \\
\text { live with a host family. }\end{array}$ & 1 & 2 & 3 & 4 & 5 \\
\hline $\begin{array}{l}\text { 18. I will not learn about the host country's culture if I live in } \\
\text { a dormitory. }\end{array}$ & 1 & 2 & 3 & 4 & 5 \\
\hline 19. A host family will teach me about their country's culture. & 1 & 2 & 3 & 4 & 5 \\
\hline $\begin{array}{l}\text { 20. The best homestay program will give me a thorough } \\
\text { orientation about living with a host family. }\end{array}$ & 1 & 2 & 3 & 4 & 5 \\
\hline $\begin{array}{l}\text { 21. I will learn more about the country's culture if I live with } \\
\text { a host family. }\end{array}$ & 1 & 2 & 3 & 4 & 5 \\
\hline $\begin{array}{l}\text { 22. I will practice the language more living with a host } \\
\text { family than in a dormitory. }\end{array}$ & 1 & 2 & 3 & 4 & 5 \\
\hline $\begin{array}{l}\text { 23. Living with a host family will improve my } \\
\text { pronunciation. }\end{array}$ & 1 & 2 & 3 & 4 & 5 \\
\hline $\begin{array}{l}\text { 24. My host family should treat me like one of their own } \\
\text { children. }\end{array}$ & 1 & 2 & 3 & 4 & 5 \\
\hline
\end{tabular}




\begin{tabular}{|l|llllll|}
\hline 25. I cannot tell my host family if I am unhappy. & 1 & 2 & 3 & 4 & 5 \\
\hline 26. My host family should give me a key to their house. & 1 & 2 & 3 & 4 & 5 \\
\hline $\begin{array}{l}\text { 27. My host family should not tell me what time to come } \\
\text { home each night. }\end{array}$ & 1 & 2 & 3 & 4 & 5 \\
\hline $\begin{array}{l}\text { 28. It is okay if there is more than one student living with my } \\
\text { host family as long as we do not speak the same native } \\
\text { language. }\end{array}$ & 1 & 2 & 3 & 4 & 5 \\
\hline
\end{tabular}

\section{Part 3: Short Answer}

Instructions: For this section, please answer the following questions. Write around 1-3 sentences per question.

1. Do you think homestays are helpful for students studying a language in a foreign country? Why or why not?

2. Do you think living with a host family is necessary to learn a foreign language? Who or why not?

3. What do you think is the best thing about homestays? 
4. What do you think is the worst thing about homestays?

5. Do you have any advice for a student who is considering a homestay?

6. If you have participated in a homestay or are currently in a homestay, have your views about homestays changed based on your experiences?

Thank you! 